\title{
3D-Conformer of Tris[60]fullerenylated cis-Tris(diphenylamino-fluorene) as Photoswitchable Charge-Polarizer on GHz-Responsive Trilayered Core-Shell Dielectric Nanoparticles
}

\author{
He Yin ${ }^{1}$, Min Wang ${ }^{1}$, Tzuyang $\mathrm{Yu}^{2}$, Loon-Seng Tan ${ }^{3}$ and Long Y. Chiang ${ }^{1, *}$ \\ 1 Department of Chemistry, University of Massachusetts Lowell, Lowell, MA 01854, USA; \\ He_Yin@student.uml.edu (H.Y.); wangmin81@gmail.com (M.W.) \\ 2 Department of Civil and Environmental Engineering, University of Massachusetts Lowell, Lowell, \\ MA 01854, USA; Tzuyang_Yu@uml.edu \\ 3 Functional Materials Division, AFRL/RXA, Air Force Research Laboratory, Wright-Patterson Air Force Base, \\ Dayton, OH 45433, USA; loon.tan@us.af.mil \\ * Correspondence: Long_Chiang@uml.edu; Tel.: +1-978-934-3663; Fax: +1-978-934-3013
}

Received: 11 July 2018; Accepted: 25 July 2018; Published: 27 July 2018

check for updates

\begin{abstract}
Novel 3D-configurated stereoisomers cis-cup-tris $\left[\mathrm{C}_{60}>\left(\mathrm{DPAF}_{-} \mathrm{C}_{9}\right)\right]$ and trans-chairtris $\left[\mathrm{C}_{60}>\left(\mathrm{DPAF}_{-} \mathrm{C}_{9}\right)\right]$ were designed and synthesized in good yields. The former, with three $\mathrm{C}_{60}>$ cages per molecule facing at the same side of the geometrical molecular cup-shape, was proposed to provide excellent binding interaction forces at the gold surface of core-shell $\gamma-\mathrm{FeO}_{\mathrm{x}} @ \mathrm{AuNP}$ nanoparticles and to direct the subsequent formation of a fullerene cage array (defined as fullerosome). Upon photoactivation of the Au-layer and cis-cup-tris $\left[\mathrm{C}_{60}>\left(\mathrm{DPAF}_{-} \mathrm{C}_{9}\right)\right]$ itself, the degree of photoinduced intramolecular $\mathrm{e}^{-}$-transfer from DPAF to a $\mathrm{C}_{60}>$ moiety was found to be largely enhanced by the accumulated plasmonic resonance energy at the near-field surface. Distribution of resulting negative charges along the outer $\left(\mathrm{C}_{60}>\right)$-derived fullerosome shell layer of the trilayered NPs was correlated with the detected photoswitchable dielectric amplification phenomena using white LED light at $1.0 \mathrm{GHz}$.
\end{abstract}

Keywords: tri[60]fullerenylated cis-cup-tris(diphenylaminofluorene); 3D-configurated cis-cup-tris $\left(\mathrm{C}_{60}\right.$ diphenylaminofluorene); trilayered core-shell gold-fullerosome nanoparticles; photoswitchable permittivity; amplification of relative dielectric constant

\section{Introduction}

Electronic charge-polarization of organic substances under the externally applied field is the basic phenomenon leading to dielectric characteristics. It can be correlated with electrons shifting within polarizable molecules or the dielectric medium showing electronic polarizability. Certain polymers including poly(vinylidene fluoride) (PVDF, having asymmetrical electron-withdrawing fluorine) [1,2], polyarylene ether nitrile (PEN, having polar cyano groups) with conducting polyaniline $[3,4]$ and azobenzene dyes (having large dipole moments of polar push-pull donor-acceptor terminal groups) [5] may exhibit such behavior; however, with a low dielectric constant. Advantages of organic dielectrics over inorganic ones, such as barium calcium titanate [6], boron nitride on graphenes [7], and titanium dioxide [8], lay on their facile chemical modification and easy processing, intrinsic excellent mechanical performance, recyclability, and multiple components blending. Example of the latter case was given by hybrid preparation of PEN on core-shell nanoparticles [9]. These dielectric materials and polymers may exhibit potential in applications of capacitor-type charge and energy storage [10-12] 
and organic photovoltaics [13]. Recently, we found [14-16] that the dielectric constant of a medium can be amplified to more than $200-350 \%$ by a photoswitching technique using the construction of multi-layered core-shell nanoparticles. They consist of two main photoresponsive components, such as organic electron $\left(\mathrm{e}^{-}\right)$-polarizable nanostructure of $\mathrm{C}_{60}\left(>\mathrm{DPAF}_{-} \mathrm{C}_{9}\right)\left(\mathbf{1}-\mathrm{C}_{9}\right.$, Figure 1$)$ and inorganic plasmonic gold nanocrystal hybrids in a form of core and shell layered nanomaterials. The degree variation of dielectric amplification depends on the core-shell composition and the distribution of polarized charges.

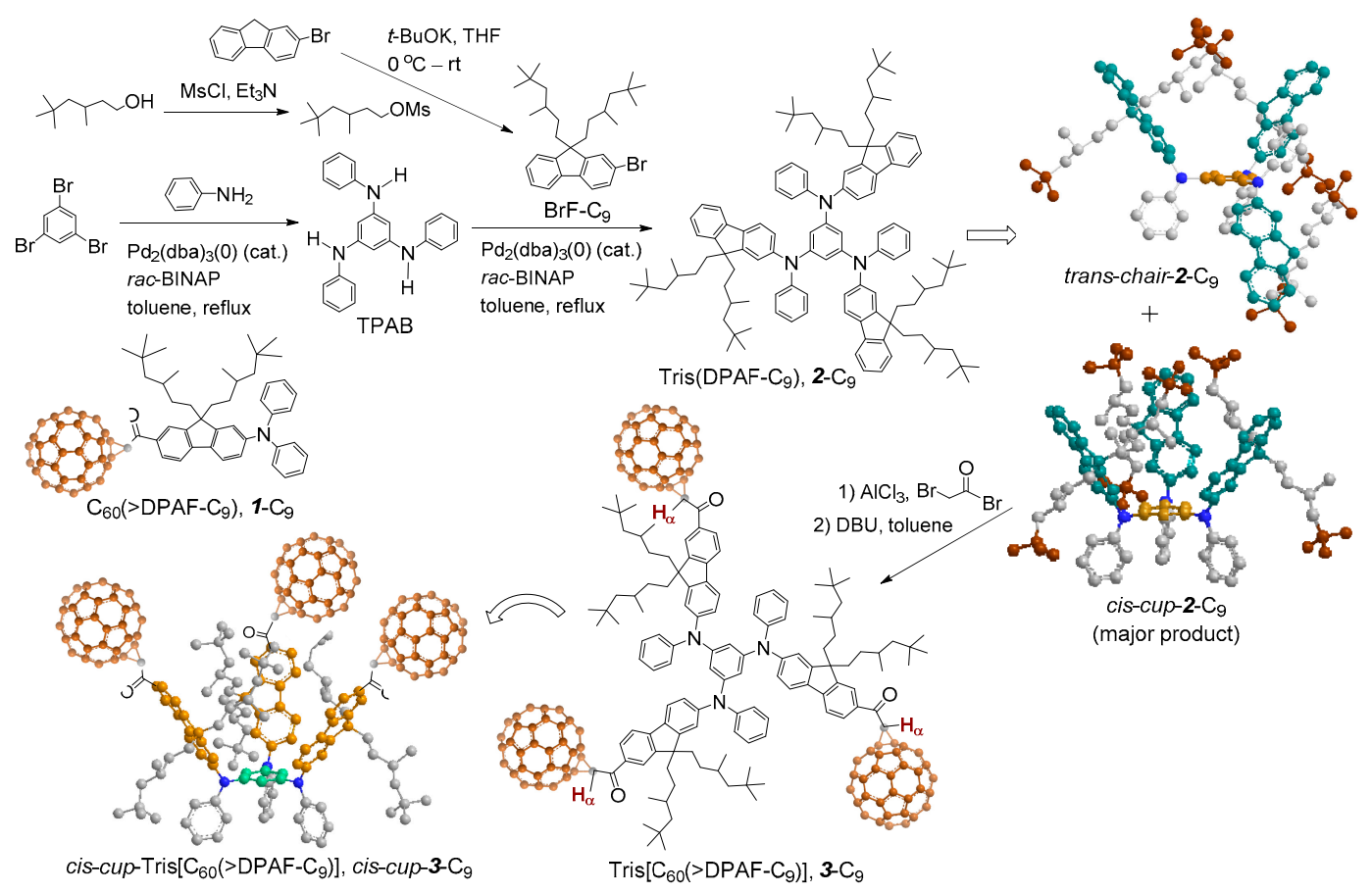

Figure 1. Synthetic route to the preparation of cis-cup-tris $\left[\mathrm{C}_{60}\left(>\mathrm{DPAF}-\mathrm{C}_{9}\right)\right]\left(\right.$ cis-cup-3- $\left.\mathrm{C}_{9}\right)$ from the isolated precursor cis-cup-tris(DPAF-C 9 ) (cis-cup-2-C ( $_{9}$ with reaction reagents provided.

The compound 1- $\mathrm{C}_{9}$ analogous nanostructure is an electronically polarizable push-pull donor-acceptor type conjugative compound having a $\mathrm{C}_{60}$ cage as the acceptor moiety and a DPAF-C $_{9}$ [9,9-di(3,5,5-trimethylhexyl)-2-diphenylaminofluorene] chromophore as the light harvesting donor antenna moiety. It is a part of the general composition of $\mathrm{C}_{60}$ (>light-harvesting antenna) ${ }_{x}$ exhibiting ultrafast inter- and intramolecular photoinduced electron-transfer processes going from the electron-donating diphenylaminofluorene moiety to the electron-accepting $\mathrm{C}_{60}$ cage moiety [17-20]. The phenomena resulted in the formation of a positively charged (DPAF) ${ }^{+} \cdot{ }_{-} \mathrm{C}_{9}$ and a negatively charged $\left(\mathrm{C}_{60}>\right)^{-} \cdot$ cage moieties, respectively. These two charge states form the foundation of our observed photoswitchable dielectric property enhancements [14-16]. Recently, we further extended the study to design and synthesize highly restricted 3D-stereoisomers based on inter-connected three DPAF- $\mathrm{C}_{9}$ chromophore units giving a structure of tris $\left(\mathrm{DPAF}^{\left.-\mathrm{C}_{9}\right)}\right.$ or $2-\mathrm{C}_{9}$ (Figure 1). The structural modification allowed us to investigate the stereo-configuration-dependence of organic fluorophore on the enhancement of their photophysical properties, including photoluminescence (PL) and electroluminescence (EL) emission in solid-state thin-films [21]. The stereochemical modification was based on the construction of 3D-geometrically branched chromophores having sterically hindered alkyl side-chains that resulted in the physical separation of each DPAF- $\mathrm{C}_{9}$ moiety of $2-\mathrm{C}_{9}$ from each other. It prevents and minimizes the tendency of planar organic $\pi$-conjugated fluorophore molecules, such as DPAF, to undergo aromatic-aromatic stacking, overlapping, and aggregation, via intermolecular hydrophobic-hydrophobic interactions, in solid state thin-films. The packing action triggers concentration-dependent self-quenching effects at excited states, resulted in the 
reduction of photophysical properties at the condensed phase. In the case of tris(DPAF- $\left.\mathrm{C}_{9}\right)$, attachment of large bulky groups at the vicinity of planar molecular benzene core region can restrict and reduce the degree of freedom in intramolecular DPAF- $\mathrm{C}_{9}$ rotation via steric hindrance, and thus the tendency of intermolecular aggregation. During the synthesis of tris(DPAF- $\left.\mathrm{C}_{9}\right)$, two stereoisomeric forms were isolated, namely, trans- and cis-tris(DPAF- $\mathrm{C}_{9}$ ) defined as trans-chair-2-C 9 and cis-cup-2-C9 [22], respectively, as shown in Figure 1. We selected the latter cup-form to undergo further attachment of a $\mathrm{C}_{60}>$ cage as the end group of each DPAF- $\mathrm{C}_{9}$ arm that resulted in a nanostructure of tris[60]fullerenylated cis-tris(diphenylaminofluorene) as cis-cup-tris[ $\mathrm{C}_{60}\left(>\mathrm{DPAF}-\mathrm{C}_{9}\right)$ ] or cis-cup-3- $\mathrm{C}_{9}$ for the photoswitchable dielectric property amplification study. This design of new stereo-isomeric structures may be beneficial for uses as positive charge carriers in enhancing photoinduced dielectric characteristics [23] and as the precursor building blocks in the synthesis of several $\mathrm{C}_{60^{-}}$and $\mathrm{C}_{70}$-based ultrafast photoresponsive nanomaterials in correlation to our recent studies [17-20]. Therefore, we applied cis-cup-3- $\mathrm{C}_{9}$ as a photoswitchable dielectric charge-polarizer in the fabrication of microwave-responsive plasmonic trilayered core-shell nanoparticles.

\section{Results and Discussion}

An electromagnetic (EM) wave consists of both components of perpendicular electric-fields and magnetic-fields. Most organic photoresponsive materials are non-magnetic. Therefore, our main design consideration of organic microwave-responsive materials in tuning a material's refractive index was based on the electric susceptibility, in terms of the degree of dielectric polarization in response to photoactivation instead of an applied electric field. In general, for disordered amorphous charge-transfer complex solids, the charge transfer events will not lead to significant alternation of the dielectric property of solids. Our approaches were to achieve the ferroelectric-like characteristics by firstly demonstrating ultrafast photoinduced intramolecular electron-transfer rate going from DPAF donor moiety to the $\mathrm{C}_{60}>$ acceptor moiety of $\mathrm{C}_{60}\left(>\right.$ DPAF- $\left.\mathrm{C}_{9}\right)\left(\mathbf{1}-\mathrm{C}_{9}\right)$ within $<130$ femtoseconds [17-20], resembling nearly spontaneous photoinduced charge-polarization action. Secondly, we then fabricated the $\mathrm{C}_{60}>$ cage assembly into an aligned partial bilayered fullerosome membrane structure [24]. This type of fullerosome consists of a $\mathrm{C}_{60}-\mathrm{C}_{60}$ cage aligned array into a nano-layer to host the polarized negative charges at the inner membrane area and all DPAF donor-antennae moieties facing outside surface of the fullerosome to host the polarized positive charges. The self-assemble action was induced by strong hydrophobic-hydrophobic $\left(\mathrm{C}_{60}>\right)-\left(\mathrm{C}_{60}>\right)$ interaction forces among fullerene cages. The resulting layered, polarized charges distribution affords a close resemblance to the characteristics of dielectrics, also as nano-capacitor-like assemblies, upon LED irradiation [14-16].

In the material's design, we replaced $1-C_{9}$ by cis-cup-tris $\left[\mathrm{C}_{60}\left(>\mathrm{DPAF}-\mathrm{C}_{9}\right)\right]$ (cis-cup-3- $\mathrm{C}_{9}$, Figure 1) as the outer shell donor-acceptor nanoconjugates on the construction of core-shell nanoparticles. It was derived from a $C_{3}$-symmetrical 1,3,5-triaminobenzene ring as the central core for connecting three fused 2-diphenylaminofluorene moieties, forming a new class of 3D-stereomeric tris(fluorenylphenylamino)-benzene as tris(DPAF- $\mathrm{C}_{9}$ ) $2-\mathrm{C}_{9}$. These 3D-stereomers faces high torsional stress at the central benzene core region that forces all fluorene chromophore groups located at the outer-edge area to be oriented in a non-coplanar 3D-configuration [22]. Two stereoisomeric

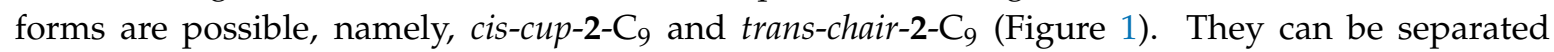
by thin-layer chromatographic technique with the former as the major product. Based on the density functional theory (DFT) calculation with the geometries optimized at the B97-D3/SVP level of theory [21], the cis-cup-form having three bis $\left(3^{\prime}, 5^{\prime}, 5^{\prime}\right.$-trimethylhexyl)fluorene moieties on 1,3,5-tris(phenylamino)benzene was found to be essentially $C_{3}$ symmetric with a higher formation tendency than the corresponding trans-chair-form. It is owing to the influence by strong dispersion interactions within the alkyl chains that are enhanceable in the presence of more polar media. Upon a $180^{\circ}$-rotation of one of three amino groups, the structure changes to produce a conformational isomer in a trans-chair-form which is less cup-like than the cis-cup-form. In principle, subsequent attachment of three $\mathrm{C}_{60}>$ cages on cis-cup-2- $\mathrm{C}_{9}$ should lead to cis-cup-3- $\mathrm{C}_{9}$ having all $\mathrm{C}_{60}>$ moieties facing outward 
from the central benzene core at the same side with each other. This will facilitate the cup-attachment on the gold layer of core-shell nanoparticles induced by the strong $\mathrm{C}_{60}$-Au binding force $[25,26]$ and, thus, enhance the distribution of polarized negative charges at gold surface bound monolayered fullerosome region, as the positive contribution to the photoswitchable relative dielectric properties.

\subsection{Synthesis of Electron-Polarizable Tris $\left[C_{60}\left(>D P A F-C_{9}\right)\right]$ Stereoisomer cis-cup-3-C 9}

Synthetic procedure for the preparation of tris(DPAF-C 9 ) with the detailed spectroscopic characterization was reported previously by us [21,22]. Geometrically conformational isomer cis-cup-2-C9 was clearly isolated from the trans-chair-stereoisomer and confirmed by the use of high performance liquid chromatography (HPLC, $\mu$ Porasil $^{\mathrm{TM}} 125 \AA, 10 \mu \mathrm{m}, 35 \times 300 \mathrm{~mm}$, mobile phase: hexane-EtOAc $(9.0: 1.0, v / v)$, flow rate: $1.0 \mathrm{~mL} / \mathrm{min}$, detector: $\mathrm{UV}$ at $\lambda 350 \mathrm{~nm}$ ) in an analytical scale. For the scale-up separation, column chromatography (CC) using the same solvent system did not provide satisfactory results. However, the application of thin-layer chromatography (TLC) technique using the solvent eluent in slightly lower polarity (hexane-ethylacetate/9.5:0.5, v/v) than those of HPLC or the CC formed an overlap band of the stereoisomers cis-cup-2- $\mathrm{C}_{9}$ and trans-chair-2- $\mathrm{C}_{9}$. By cutting the corresponding fluorescent TLC band of tris(DPAF- $\mathrm{C}_{9}$ ) into two portions and performing several repeated TLC procedures, we were able to significantly increase the degree of product purity sufficiently enough to allow our confirmation of their entity by ${ }^{1} \mathrm{H}$ NMR spectrum [21,22]. It indicated a higher $R_{\mathrm{f}}$ value for cis-cup-2- $\mathrm{C}_{9}$ than that of trans-chair-2- $\mathrm{C}_{9}$. With a $C_{3}$ symmetry in structure, the former displayed a differentiable singlet peak for three central benzene protons $\left(\right.$ cis- $\left.\mathrm{H}_{\mathrm{b}}\right)$ at $\delta 6.55$ (Figure 2(Aa)), while the latter with a less symmetry resulted in two proton peaks $\left(\right.$ trans- $\left.\mathrm{H}_{\mathrm{b}}\right)$ at $\delta 6.48$ $(1 \mathrm{H})$ and $6.55(2 \mathrm{H})$.
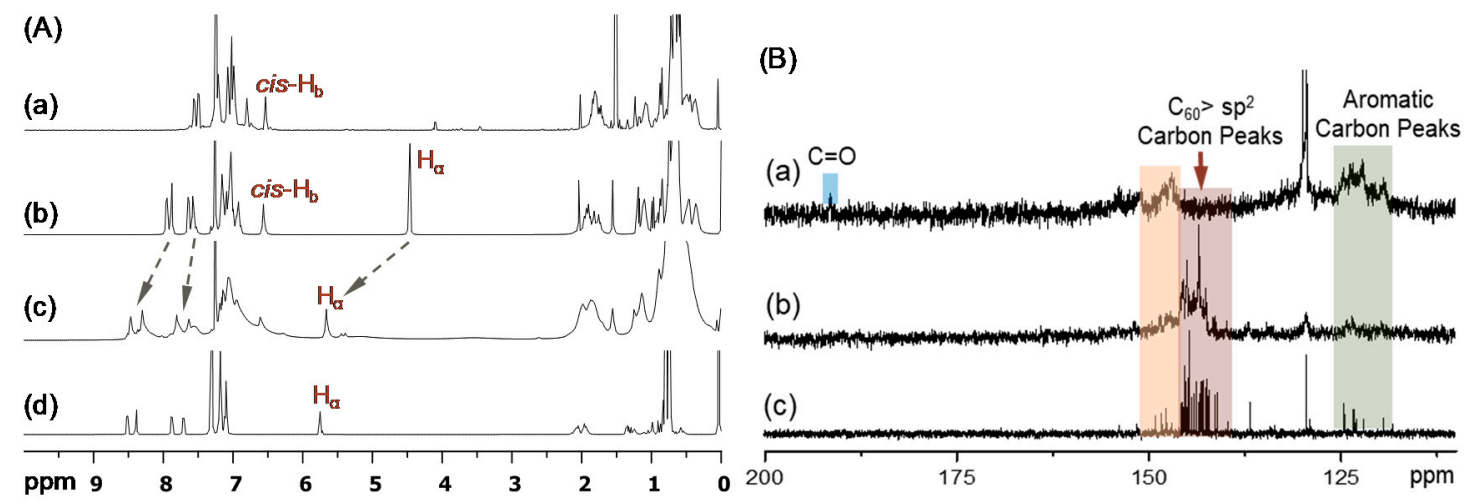

Figure 2. (A) ${ }^{1} \mathrm{H}$ NMR spectra $\left(\mathrm{CDCl}_{3}\right)$ of (a) cis-cup-tris(DPAF-C 9$)$ (cis-cup-2-C9),

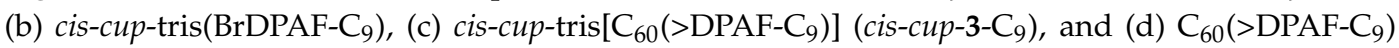
as a reference for comparison. (B) ${ }^{13} \mathrm{C}$ NMR spectra of (a) cis-cup-tris(BrDPAF-C 9 ),

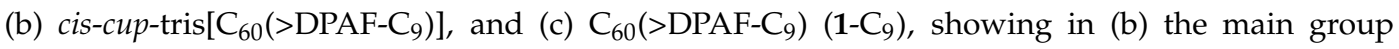
of fullerenyl $\mathrm{sp}^{2}$ carbon peaks at $\delta 140-147$ that indicated the attachment of $\mathrm{C}_{60}>$ cages on 2-C as compared with those of $(\mathrm{Bc})$.

Prior to the attachment of three $\mathrm{C}_{60}>$ cages on cis-cup-2- $\mathrm{C}_{9}$, it was functionalized by the Friedel-Crafts acylation at C7 position of diphenylaminofluorene moiety with $\alpha$-bromoacetyl bromide in the presence of aluminum chloride (6.0 eq.) in 1,2-dichloroethane at $0{ }^{\circ} \mathrm{C}$ to ambient temperature overnight to afford the corresponding $\alpha$-bromoacetylfluorene derivative, as the intermediate step of reactions. It resulted in yellow semi-solids in 53\% yield of $c i s-N^{1}, N^{3}, N^{5}$-tris(7- $\alpha$-bromoacetyl-9,9$\operatorname{di}\left(3^{\prime}, 5^{\prime}, 5^{\prime}\right.$-trimethyl-1'-hexyl)fluoren-2-yl)-1", $3^{\prime \prime}, 5^{\prime \prime}$-tris(phenylamino)benzene as cis-cup-tris(BrDPAF$\mathrm{C}_{9}$ ). It was purified by either column or TLC chromatography (silica gel, hexane-toluene, 3:2, $R_{\mathrm{f}}=0.3$

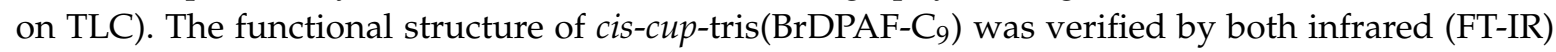
and ${ }^{1} \mathrm{H}$ NMR spectra with the former showing a strong carbonyl $(-\mathrm{C}=\mathrm{O})$ stretching absorption 
band centered at $1675 \mathrm{~cm}^{-1}$ indicating this functional group being linked on a phenyl moiety since a clear band absorption shift from $1725 \mathrm{~cm}^{-1}$, normally detectable for an alkyl carbonyl group, was evident. In the case of ${ }^{1} \mathrm{H}$ NMR spectrum, tris $\left(B r-D P A F-C_{9}\right)$ displayed characteristic new peak signals of two methylene protons $\left(\mathrm{H}_{\alpha}\right)$ next to the carbonyl group of the $\alpha$-bromoacetyl moiety at $\delta 4.46$ (Figure 2(Ab)). Subsequence attachment of a $\mathrm{C}_{60}>$ cage to each of three DPAF moieties was made via a cylopropylacetyl bridge by the treatment of three $\alpha$-bromoacetylfluorene moieties of cis-cup-tris(BrDPAF- $C_{9}$ ) with $\mathrm{C}_{60}$ in toluene in the presence of DBU at ambient temperature for $8.0 \mathrm{~h}$. An excessive amount of $\mathrm{C}_{60}$ (4.5 eq.) was applied to avoid the formation of $\mathrm{C}_{60}$-bisadducts or trisadducts during the cyclopropanation reaction. The product of cis-cup-tris[ $\left.\mathrm{C}_{60}\left(>\mathrm{DPAF}-\mathrm{C}_{9}\right)\right]$ stereoisomer as cis-cup-3- $\mathrm{C}_{9}$ was confirmed by the evidence of changing solubility characteristics matching those of $\mathrm{C}_{60}$ and a slight shift of cyclopropyl keto group absorption in IR spectrum to $v_{\max }$ $1627 \mathrm{~cm}^{-1}$, which was assigned to the carbonyl stretching band. It was also accompanied by two typical fullerenyl cage signals at $v_{\max } 575(\mathrm{w})$ and $529(\mathrm{~s}) \mathrm{cm}^{-1}$. These two bands are characteristic absorptions used to provide evidence of $\left(\mathrm{C}_{60}>\right)$-related monoadduct with relative intensity ratio differentiable from those of starting $\mathrm{C}_{60}$ itself. They will disappear from the spectrum once becoming a $\left(\mathrm{C}_{60}>\right)$-bisadduct. Therefore, this IR technique was applied often in the [60]fullerenyl product structure verification. In addition, disappearance of $\alpha$-proton peaks of the $\alpha$-bromoacetyl group at $\delta 4.46$ (Figure 2(Ab)) with the appearance of new peaks centered at $\delta 5.67$ (Figure 2(Ac)) can be indicative of successful formation of the cyclopropanyl keto-bridge between a $\mathrm{C}_{60}>$ cage and the fluorene moiety, using previously reported $\mathrm{C}_{60}\left(>\mathrm{DPAF}_{\mathrm{C}} \mathrm{C}_{9}\right.$ ) characterization (Figure 2(Ad)) as the reference [17]. The latter peak $\delta 5.67$ was assigned to the chemical shift of $\alpha$-proton $\left(\mathrm{H}_{\alpha}\right)$ of $3-\mathrm{C}_{9}$ indicated in Figure 1. Its large down-fielded shift from the normal chemical shift value of a alkyl acetyl proton at $\sim \delta 2.1-2.6$ is due to the influence of strong [60] fullerenyl current in the close vicinity. Accordingly, the detection of $\delta 5.67$ peak can also be served as the verification of short covalent-bonding between $\mathrm{C}_{60}>$ and DPAF moieties. The half-height width of $\mathrm{H}_{\alpha}$ peak in Figure 2(Ac) is slightly wider than that of Figure 2(Ab) that revealed less symmetrical environment among three $\mathrm{H}_{\alpha}$ protons of cis-cup-3- $\mathrm{C}_{9}$. Similarly, by using ${ }^{13} \mathrm{C}$ NMR spectrum of $\mathrm{C}_{60}\left(>\mathrm{DPAF}-\mathrm{C}_{9}\right)$ (Figure $2(\mathrm{Bc})$ ) as the reference for comparison, we were able to detect calculated 29 fullerenyl $\mathrm{sp}^{2}$ carbon peaks corresponding to the $C_{60}>$ moiety $\left(C_{2}\right.$ symmetry) of cis-cup-tris $\left[\mathrm{C}_{60}\left(>\mathrm{DPAF}_{-} \mathrm{C}_{9}\right)\right]$ as a matching multi-peak band in the range of $\delta 140-147$ (Figure 2(Bb)). The reduced spectrum resolution is due to the increasing molecular complexity along with the reduced solubility of cis-cup-3-C 9 .

\subsection{Synthesis of cis-cup-Tris $\left[C_{60}\left(>D P A F-C_{9}\right)\right]$-Encapsulated Core-Shell Nanoparticles}

Synthetic procedures for the preparation of core-shell $\gamma-\mathrm{FeO}_{x} @$ AuNP nanoparticles (4-NPs) in an average particle diameter of $\sim 20 \mathrm{~nm}$ were reported by us recently [14,15]. A slightly modified method was applied in this study to afford similar results based on the verification by transmission electron microscopy (TEM) micrographs and microanalyses of energy dispersive x-ray spectra (EDS). Subsequent encapsulation of $\gamma-\mathrm{FeO}_{x} @$ AuNPs by cis-cup-tris[ $\left[\mathrm{C}_{60}\left(>\mathrm{DPAF}-\mathrm{C}_{9}\right)\right]$ leading to the formation of trilayered core-shell NPs (Figure 3) was performed by mixing these two components in a predefined ratio in solvent under ultrasonication. The initial binding force of cis-cup-3- $\mathrm{C}_{9}$ to $\gamma-\mathrm{FeO}_{\mathrm{x}} @ \mathrm{AuNP}$ was governed by strong binding interaction forces of $C_{60}>$ cages to the gold surface $[26,27]$ that should result in the partial replacement of 1-octanethiol capping molecules on the gold surface via alkylthiol ligand- $\mathrm{C}_{60}>$ exchange induced by sonochemical energy to invert cis-cup-3- $\mathrm{C}_{9}$ molecules under ultrasonication. The exchange should form a monolayer of cis-cup-tris $\left[\mathrm{C}_{60}\left(>\mathrm{DPAF}-\mathrm{C}_{9}\right)\right]$ with the orientation of all three $\mathrm{C}_{60}>$ cages per nanomolecule in a cup-capping manner facing on the surface of Au layer with interlinked three DPAF- $C_{9}$ moieties facing outward. Attachment of additional cis-cup-3- $\mathrm{C}_{9}$ nanomolecules will follow the strong hydrophobic-hydrophobic interactions among $\left(C_{60}>\right)-\left(C_{60}>\right)$ cages to form a partial trilayered fullerosome membrane resembling that of reported fullerenyl nanovesicle [24]. Since all encapsulated magnetic nanoparticles were physically removed from the container solution by the assistance of an external permanent magnet and washed repeatedly 
by ethanol and diethyl ether, we were able to ensure the products being free from residual non-binding cis-cup-3- $\mathrm{C}_{9}$ molecules at the NP surface. We assigned the resulting trilayered core-shell nanostructures of $\left(\gamma-\mathrm{FeO}_{\mathrm{x}} @ \mathrm{AuNP}\right) @\left\{\text { cis-cup-tris }\left[\mathrm{C}_{60}\left(>\mathrm{DPAF}-\mathrm{C}_{9}\right)\right]\right\}_{\mathrm{n}}$ as 5-NPs.

TEM micrographs of Figure 3 showed the morphology and topography of NPs that indicated a roughly homogeneous narrow size distribution of the parent $\gamma-\mathrm{FeO}_{x} \mathrm{NPs}$ (Figure $3 \mathrm{a}$ ) at a diameter of $\sim 20 \mathrm{~nm}$, on average. Subsequent deposition of solid gold nanocrystals on the surface of $\gamma-\mathrm{FeO}_{\mathrm{x}} \mathrm{NPs}$ to a structure of core-shell $\gamma-\mathrm{FeO}_{\mathrm{x}} @ \mathrm{AuNP}$ (4-NP) was controlled to a shell layer thickness of 6.0-8.0 nm by the calculated quantity of $\mathrm{HAuCl}_{4}$ applied. This thickness was measured by the comparison of average particle size between Figure 3a,b, where the latter displayed much higher contrast of the Au layer shell. With the encapsulation of 4-NPs by cis-cup-3- $\mathrm{C}_{9}$-derived fullerosome (array of $\mathrm{C}_{60}>$ cages) as the outer shell layer, the morphology of soft organic materials in lighter contrast covering all hard nanoparticles can be observed that allowed us to measure an average thickness of roughly $10 \mathrm{~nm}$ (Figure 3c), matching well with the weight ratio of 4-NPs and cis-cup-3-C9 applied in the core-shell nanoparticle fabrication.
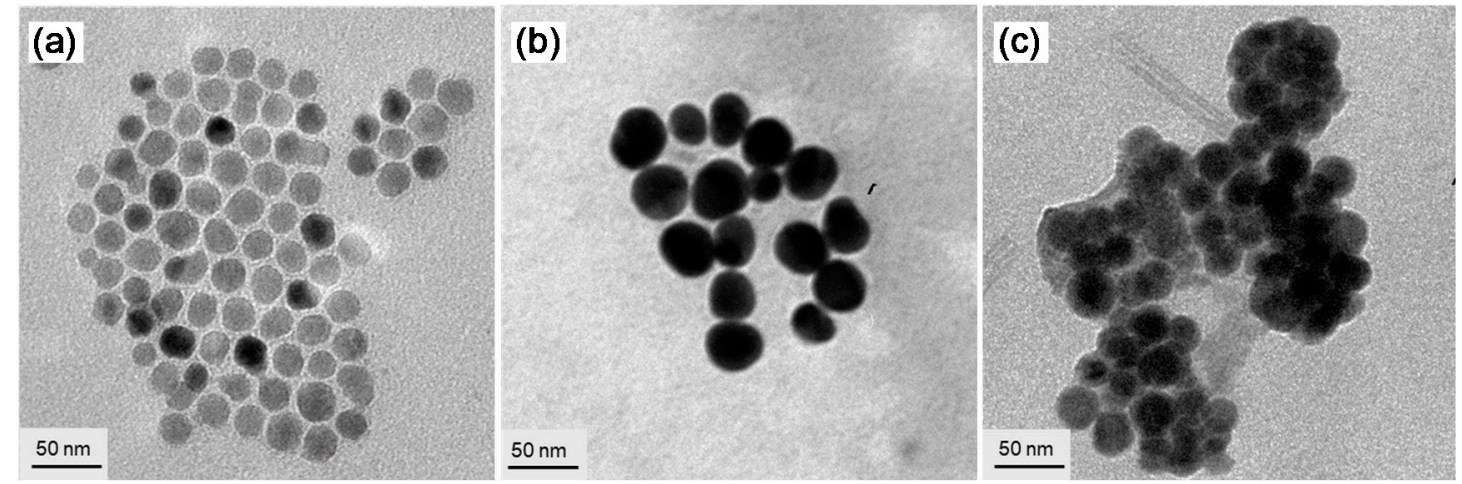

Figure 3. TEM micrograph images of (a) $\gamma$-FeO NPs, $_{x}$ (b) $\gamma$-FeO - $_{x}$ AuNP (4-NPs), and (c) $\left(\gamma-\mathrm{FeO}_{\mathrm{x}} @ \mathrm{AuNP}\right) @\left\{\text { cis-cup-tris }\left[\mathrm{C}_{60}\left(>\mathrm{DPAF}-\mathrm{C}_{9}\right)\right]\right\}_{\mathrm{n}}$ (5-NPs), showing evolution of particle morphology changes and the soft organic material encapsulation on dark nanoparticles on the latter micrograph.

\subsection{Physical Properties of cis-cup-Tris $\left[C_{60}\left(>D P A F-C_{9}\right)\right]$ and Its Encapsulated Core-Shell Nanoparticles}

Photophysical properties of cis-cup-tris $\left[\mathrm{C}_{60}\left(>\mathrm{DPAF}-\mathrm{C}_{9}\right)\right]$ are dominated by two components, namely, $\mathrm{C}_{60}>$ cages as the electron $\left(\mathrm{e}^{-}\right)$-acceptors and light-harvesting DPAF antenna units as electron $\left(\mathrm{e}^{-}\right)$-donors. Both components are photoresponsive at a different wavelength range. For example, optical absorption of $\mathrm{C}_{60}>$ cages occurs mainly the band centered at $335 \mathrm{~nm}\left(1.76 \times 10^{5} \mathrm{~L} \mathrm{~mol}^{-1}\right.$ $\left.\mathrm{cm}^{-1}\right)$ [17], whereas the band centered at $402 \mathrm{~nm}\left(4.19 \times 10^{4} \mathrm{~L} \mathrm{~mol}^{-1} \mathrm{~cm}^{-1}\right)$ is attributed to the absorption of DPAF moieties, as shown in the UV-vis spectra of Figure 4c. Characteristics of the latter band were compared with that of cis-cup-2-C9 (Figure 4a), cis-cup-tris(BrDPAF-C9) (Figure 4b), and $\mathrm{C}_{60}\left(>\mathrm{DPAF}_{-}\right)\left(\mathbf{1}-\mathrm{C}_{9}\right.$, Figure $\left.4 \mathrm{~d}\right)$ showing a clear bathochromic shift of the 353-nm band of the former to $395 \mathrm{~nm}\left(1.10 \times 10^{5} \mathrm{~L} \mathrm{~mol}^{-1} \mathrm{~cm}^{-1}\right)$, which is matching roughly with the 404-nm band of 1- $\mathrm{C}_{9}$ and the 402-nm band of cis-cup-3- $\mathrm{C}_{9}$ for the peak assignment. This assignment was also consistent with the observation of 2.9-folds higher in the absorption extinction coefficient $(\varepsilon)$ value for cis-cup-tris(BrDPAF-C9), having three DPAF moieties per molecule, as comparing with that of 1-C9 with one DPAF moiety per molecule. Upon the attachment of three $\mathrm{C}_{60}>$ cages, optical absorptions of fullerene moieties of cis-cup-3- $\mathrm{C}_{9}$ became dominating in the spectrum with a much higher $\varepsilon$ value for the 335-nm band (Figure 4c). It was accompanied by a weak characteristic (forbidden) steady state absorption band of the $\mathrm{C}_{60}>$ moiety appearing at $692 \mathrm{~nm}$ (the insert of Figure $4 \mathrm{c}$ ) that provided further confirmation of a fullerene conjugate structure. 
Interestingly, distinctly 3.3-folds lower in the $\varepsilon$ value of the $402 \mathrm{~nm}$ peak in Figure $4 \mathrm{c}$ than that of 1- $\mathrm{C}_{9}$, making it as a shoulder band to the main $\mathrm{C}_{60}>$ absorption, was interpreted by a phenomenon likely caused by the specific molecular 3D-conformation of cis-cup-tris[C 60 (>DPAF-C 9$)$. Owing to good solubility and compatibility of fullerenes to toluene solvent used, the orientation of three $\mathrm{C}_{60}>$ cages was likely to face outward into the solvent phase while DPAF moieties were hidden inside the partially aggregated cluster nanoparticle. The hypothesis was also verified by observation of the distinguishable solubility decrease of cis-cup-3- $\mathrm{C}_{9}$ in $\mathrm{CHCl}_{3}$; however, increase in toluene and $\mathrm{CS}_{2}$ matches well with the solubility characteristics of $\mathrm{C}_{60}$.

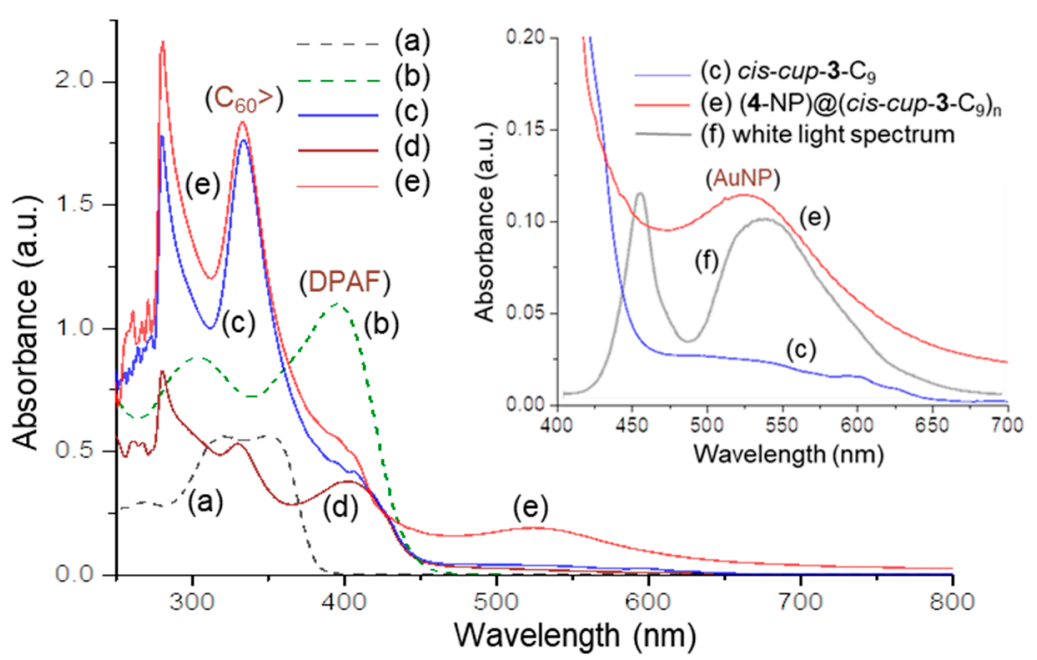

Figure 4. UV-vis spectra of (a) cis-cup-tris(DPAF-C9) (cis-cup-2-C 9 ), (b) cis-cup-tris(BrDPAF-C9), (c) cis-cup-tris $\left[\mathrm{C}_{60}\left(>\mathrm{DPAF}-\mathrm{C}_{9}\right)\right]($ cis-cup-3-C 9$)$, (d) $\mathrm{C}_{60}\left(>\mathrm{DPAF}_{-} \mathrm{C}_{9}\right)\left(\mathbf{1}-\mathrm{C}_{9}\right),(\mathrm{e})(\mathbf{4}-\mathrm{NP}) @(\text { cis-cup-3-C } 9)_{\mathrm{n}}$ (5-NPs), and (f) white light emission spectrum, where (a) and (b) were taken in EtOAc and (c), (d), and (e) were taken in toluene. The concentration of all samples is $1.0 \times 10^{-5} \mathrm{M}$.

Our study of photoswitchable dielectric amplification phenomena is based on photoexcited plasmonic resonance energy transfer to induce the intramolecular charge polarization of cis-cup-tris $\left[\mathrm{C}_{60}\left(>\mathrm{DPAF}_{-} \mathrm{C}_{9}\right)\right]$ forming the corresponding dielectric ion-radical components $\left(\mathrm{C}_{60}>\right)^{-} \cdot$ and $\mathrm{DPAF}^{+} \cdot-\mathrm{C}_{9}$. In this event, $\mathrm{C}_{60}>$ served as an electron ( $\left.\mathrm{e}^{-}\right)$-acceptor, whereas light-harvesting DPAF antenna worked as an electron $\left(\mathrm{e}^{-}\right)$-donor. Accordingly, we first investigated the characteristics of redox potentials of both $\mathrm{C}_{60}>$ and DPAF moieties in the 3D-configurated nanostructure. Measurements of the cyclic voltammetry $(\mathrm{CV})$ were carried out on the sample of cis-cup-3- $\mathrm{C}_{9}$ in a mixture of toluene and ( $n$-butyl $)_{4} \mathrm{~N}^{+}-\mathrm{PF}_{6}{ }^{-}$electrolyte, using $\mathrm{Pt}$ as both working and counter electrodes and $\mathrm{Ag} / \mathrm{AgCl}$ as the reference electrode. To provide a clear data interpretation, $\mathrm{CV}$ characteristics of $\mathrm{C}_{60}$ (>DPAF-C 9 ) were applied as the reference under variation of cyclic oxidation and reduction voltages vs. $\mathrm{Ag} / \mathrm{Ag}^{+}$from -2.0 to $1.5 \mathrm{~V}$. It displayed one reversible oxidation $\left({ }^{1} E_{\mathrm{Ox}}\right.$ of $\left.0.95 \mathrm{~V}\right)$-reduction $\left({ }^{1} E_{\text {red }}\right.$ of $\left.1.07 \mathrm{~V}\right)$ cycle wave at positive voltages and at least two reversible reduction $\left({ }^{1} E_{\text {red }}\right.$ of $-0.43 \mathrm{~V}$ and ${ }^{2} E_{\text {red }}$ of $-0.88 \mathrm{~V}$ )-oxidation $\left({ }^{1} E_{\mathrm{ox}}\right.$ of $-0.62 \mathrm{~V}$ and ${ }^{2} E_{\mathrm{ox}}$ of $\left.-1.10 \mathrm{~V}\right)$ cycle waves at negative voltages (Figure 5(Ac)). These potential values were compared by those of a set of separated molecular components using a $\mathrm{C}_{60}>$ monoadduct and cis-cup-tris(DPAF-C 9 ) as models for confirmation, showing reversible ${ }^{1} E_{\text {red }} /{ }^{1} E_{\mathrm{ox}}$ of $-0.40 /-0.71 \mathrm{~V},{ }^{2} E_{\mathrm{red}} /{ }^{2} E_{\mathrm{ox}}$ of $-0.82 /-1.14 \mathrm{~V}$, and ${ }^{3} E_{\mathrm{red}} /{ }^{3} E_{\mathrm{ox}}$ of $-1.33 /-1.62 \mathrm{~V}$ vs. $\mathrm{Ag} / \mathrm{Ag}^{+}$for the $\mathrm{C}_{60}>$ monoadduct (Figure 5(Aa)) and one reversible cyclic wave of ${ }^{1} E_{\mathrm{ox}} /{ }^{1} E_{\text {red }}$ as $0.93 / 1.03 \mathrm{~V}$ for cis-cup-tris(DPAF-C9) (Figure 5(Ab)). Once the compound 1-C9 was molecularly tripled to cis-cup-3- $\mathrm{C}_{9}$, the cyclic redox wave corresponding to DPAF moieties at positive voltages fully disappeared, as shown in Figure $5(\mathrm{Ad})$. However, two clearly reversible ${ }^{1} E_{\text {red }} /{ }^{1} E_{\text {ox }}$ $(-0.23 /-0.55 \mathrm{~V})$ and ${ }^{2} E_{\text {red }} /{ }^{2} E_{\mathrm{ox}}(-0.75 /-0.99 \mathrm{~V})$ with one less obvious cyclic wave of ${ }^{3} E_{\mathrm{red}} /{ }^{3} E_{\mathrm{ox}}$ $(-0.97 /-1.15 \mathrm{~V})$ vs. $\mathrm{Ag} / \mathrm{Ag}^{+}$corresponding to the redox characteristics of $\mathrm{C}_{60}>$ moieties of cis-cup-3- $\mathrm{C}_{9}$ 
were observed. This revealed the occurrence of a partial one-electron oxidation process of $\mathrm{e}^{-}-\mathrm{donor}$ DPAF- $C_{9}$ moiety in the structure of cis-cup-3- $\mathrm{C}_{9}$ in the presence of three $\mathrm{C}_{60}>$ cages. This inhibited the further electron-oxidation event in a clear manner. Since $\mathrm{C}_{60}>$ is capable of undergoing at least three reversible reduction/oxidation waves (Figure 5(Aa)), partial $\mathrm{e}^{-}$-transfer from DPAF may not give significant influence on its $\mathrm{CV}$ diagram, except the first and second reduction potentials being modified from -0.43 to -0.23 and -0.88 to $-0.75 \mathrm{~V}$ vs. $\mathrm{Ag} / \mathrm{Ag}^{+}$, respectively.

Most importantly, we were able to apply the white LED light irradiation (30 min) concurrent with the CV measurement to obtain the insight of redox characteristics of cis-cup-3- $\mathrm{C}_{9}$ under similar photoexcitation conditions used in the dielectric property measurements of the same compound in a form of core-shell nanoparticles, as described below. As a result, Figure 5(Ae) displayed a similar cyclic wave profiles as those of Figure $5(\mathrm{Ad})$ showing two clearly reversible waves with ${ }^{1} E_{\text {red }} /{ }^{1} E_{\text {ox }}(-0.32 /-0.55 \mathrm{~V})$ and ${ }^{2} E_{\text {red }} /{ }^{2} E_{\text {ox }}(-0.70 /-0.99 \mathrm{~V})$ vs. $\mathrm{Ag} / \mathrm{Ag}^{+}$that was attributed to the redox characteristics of $\mathrm{C}_{60}>$ moieties. No clear oxidation waves of DPAF moieties were detected that was indicative of an effective intramolecular $\mathrm{e}^{-}$-transfer from DPAF-C 9 to $\mathrm{C}_{60}>$ upon light irradiation to produce three ion-radical pairs per molecule as cis-cup-tris $\left[\mathrm{C}_{60}{ }^{-} \cdot\left(>\mathrm{DPAF}-\mathrm{C}_{9}\right)^{+} \cdot\right]_{\text {. At this }}$ polarized charge-form, DPAF moieties were not able to undergo further electron-oxidation process, consistent with the observed data. Furthermore, these CV results may be correlated with or indicative of similar charge-polarization phenomena to occur in the solid state of (cis-cup-3-C9)-encapsulated core-shell 5-NPs.
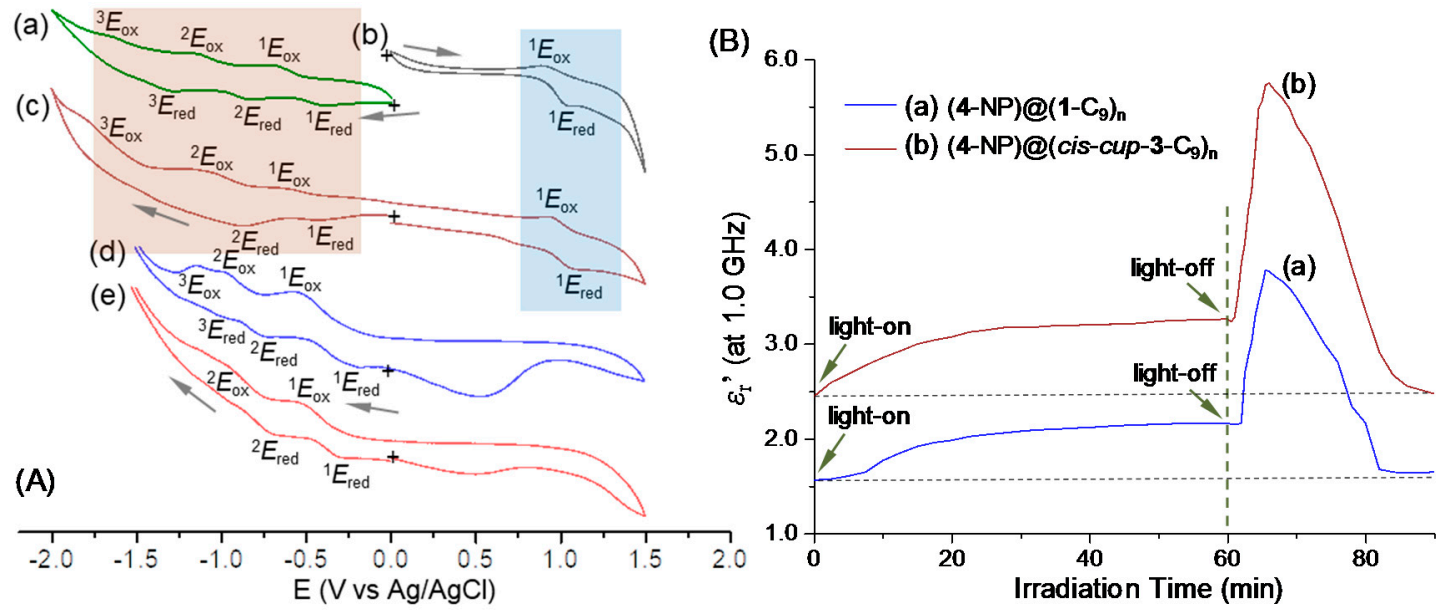

Figure 5. (A) Cyclic voltammograms (CV) of (a) $\mathrm{C}_{60}>$, (b) cis-cup-tris(DPAF- $\mathrm{C}_{9}$ ), (c) $\mathrm{C}_{60}$ (>DPAF-C (D) )

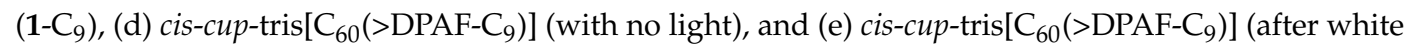
LED light irradiation for $30 \mathrm{~min}$ ) at different voltages vs $\mathrm{Ag} / \mathrm{Ag}^{+}$in a solution concentration of

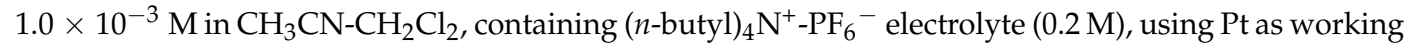
and counter electrodes and $\mathrm{Ag} / \mathrm{AgCl}$ as the reference electrode at a scan rate of $10 \mathrm{mV} / \mathrm{s}$. (B) Irradiation time-dependent relative dielectric constant $\left(\varepsilon_{\mathrm{r}}{ }^{\prime}\right)$ amplification of trilayered core-shell nanoparticles of (a) $\left(\gamma-\mathrm{FeO}_{\mathrm{x}} @ \mathrm{AuNP}\right) @\left[\mathrm{C}_{60}\left(>\mathrm{DPAF}-\mathrm{C}_{9}\right)\right]_{\mathrm{n}}(6-\mathrm{NPs})$ and $(\mathrm{b})\left(\gamma-\mathrm{FeO}_{\mathrm{x}} @ \mathrm{AuNP}\right) @\left\{\text { cis-cup-tris}\left[\mathrm{C}_{60}\left(>\mathrm{DPAF}-\mathrm{C}_{9}\right)\right]\right\}_{\mathrm{n}}$ (5-NPs) at the frequency of $1.0 \mathrm{GHz}$. White LED light irradiation period was $60 \mathrm{~min}$.

The reflectivity of a subject is controlled by the refractive index of the subject surface medium that is a function of the product of permittivity $\left(\varepsilon_{\mathrm{r}}\right)$ in a complex form and permeability $(\mu)$. Both are relevant material parameters in response to incident electromagnetic waves. The former complex permittivity can be presented by the equation $\varepsilon_{\mathrm{r}}{ }^{*}=\varepsilon_{\mathrm{r}}{ }^{\prime}-i \varepsilon_{\mathrm{r}}{ }^{\prime \prime}$, where $\varepsilon_{\mathrm{r}}{ }^{\prime}$ is the real part as the relative dielectric constant and $\varepsilon_{\mathrm{r}}{ }^{\prime \prime}$ is the imaginary part as the loss factor. The former parameter $\varepsilon_{\mathrm{r}}{ }^{\prime}$ is dependent on charge-polarization of the material at the wavelength of measurements. In the experimental data collection, the complex relative electric permittivity (and) values were measured in terms of complex reflection coefficient of electromagnetic waves in proportion to a complex scattering parameter, defined 
as $S_{11}$. The scattering parameter $S_{11}$ was measured by a high-performance coaxial probe (Agilent 85070E) [27]. It was then converted to complex relative electric permittivity $\left(\varepsilon_{\mathrm{r}}{ }^{*}\right)$ values using the Nicolson-Ross algorithm [28]. From this measurement and calculation, the value of $\varepsilon_{r}{ }^{\prime}$ was derived.

Surface plasmon resonance (SPR) energy phenomena has been demonstrated and applied in many technological areas including the use of it as an alternative means to increase either light absorption or scattering in a thin film to enhance solar cells efficiency $[29,30]$. In principle, SPR energy occurs as the result of collective oscillation of surface electrons in gold nanoparticles that is induced by the interaction with the incident light. It leads to polarization with the formation of polaritons leading to the influence of absorption cross-section enhancement and light emitting [31]. In our study, we applied core-shell nanoparticles to investigated the possibility of tuning the SPR energy band to match with absorptions of dielectric materials for the induced intramolecular electron polarization that led to the modulation of dielectric constant and related physical property of the material layer on core-shell nanoparticles of 5-NPs. The approach coincides with our recent results of ultrafast photoinduced intramolecular $\mathrm{e}^{-}$-transfer phenomena in femtoseconds $[19,20]$. Therefore, we found that a near-field effect within a few nanometers was crucial to enhance SPR energy accumulation during the energy-transfer event between plasmonic AuNPs and $\mathrm{C}_{60}$-(antenna) $)_{\mathrm{x}}$ core-shell layers by direct contacts. Accordingly, we assembled a multiple layered structure of NPs having an inner magnetic $\gamma-\mathrm{FeO}_{x} @ A u N P$ core encapsulated by an outer cis-cup-tris $\left[\mathrm{C}_{60}\left(>\mathrm{DPAF}-\mathrm{C}_{9}\right)\right]$ shell, as described above. The NP fabrication was coupled by the control of the layer thickness of cis-cup-3- $\mathrm{C}_{9}$ in terms of the quantity weight ratio to that of $\gamma-\mathrm{FeO}_{\mathrm{x}} @ \mathrm{AuNP}(4-\mathrm{NPs})$.

We first evaluated the degree difference of dielectric property amplification between $1-C_{9}$ (giving 6-NPs) and cis-cup-3- $\mathrm{C}_{9}$ (giving 5-NPs) using the same plasmonic core-shell $\gamma$-FeO $\mathrm{O}_{\mathbf{x}} @ \mathrm{AuNP}$ core. As a result, Figure $5 \mathrm{~B}$ showed irradiation time-dependent relative dielectric constant $\left(\varepsilon_{\mathrm{r}}{ }^{\prime}\right)$ curves of 5-NPs and 6-NPs taken at the microwave frequency of $1.0 \mathrm{GHz}$ during and after a 60-min white LED light illumination (corresponding to a total light fluence of $12.8 \mathrm{~J} / \mathrm{cm}^{2}$ ). Apparently, microwave EM wave showed a higher sensitivity to the NP surface materials for us to note the detected initial dielectric constant value at the time zero min being comparable in value to that of organic $1-\mathrm{C}_{9}\left(\varepsilon_{\mathrm{r}}{ }^{\prime}{ }^{\prime} \min =1.55\right)$ and cis-cup-3- $\mathrm{C}_{9}\left(\varepsilon_{\mathrm{r}}{ }^{\prime} 0 \min =2.48\right)$ even though the inner shell layer of AuNPs and the core $\gamma-\mathrm{FeO}_{\mathrm{x}}$ NPs having a much higher $\varepsilon_{\mathrm{r}}^{\prime} 0$ min $(=9.0)$ value. A slightly higher $\varepsilon_{\mathrm{r}}{ }^{\prime} 0 \min$ for the latter is interesting since higher dielectric constant organics may be advantageous in energy devices. In all experiments, white light illumination led to a slight rise in temperature to $35-45^{\circ} \mathrm{C}$ in the first $15 \mathrm{~min}$. Slight increase of chamber temperatures away from $25^{\circ} \mathrm{C}$ resulted in a small increase of the $\varepsilon_{\mathrm{r}}{ }^{\prime}$ value in a similar degree among these two samples. The $\varepsilon_{\mathrm{r}}{ }^{\prime}$ value was then remaining relatively steady during the rest of irradiation period up to $60 \mathrm{~min}$. Upon turning-off the light at the end of 60 -min irradiation, we observed a large sharp raise of the $\varepsilon_{\mathrm{r}}{ }^{\prime}$ value for both samples while the chamber temperature dropped quickly back to $25^{\circ} \mathrm{C}$. Sharp increase of the permittivity at the light-off stage was found to reach a peak maximum $\left(\varepsilon_{\mathrm{r}}{ }^{\prime}\right.$ max $)$ value of 5.75 for 5-NPs (Figure $5(\mathrm{Bb})$ ) and 3.75 for 6-NPs (Figure 5(Ba)). They can be accounted by a ratio of $\varepsilon_{\mathrm{r}}{ }^{\prime} \max / \varepsilon_{\mathrm{r}}{ }^{\prime}{ }_{\text {min }}$ in a 2.35- and 2.42-fold increase for 5-NPs and 6-NPS, respectively. Similar calculations based on the ratio of $\varepsilon_{\mathrm{r}}{ }^{\prime} \max / \varepsilon_{\mathrm{r}}{ }^{\prime} 60 \mathrm{~min}$ (the $\varepsilon_{\mathrm{r}}{ }^{\prime}$ value at time 60-min) were found to be 1.76- and 1.74-fold increase in the $\varepsilon_{\mathrm{r}}{ }^{\prime}$ value for 5-NPs $\left(\varepsilon_{\mathrm{r}}{ }^{\prime} 60 \mathrm{~min}=3.26\right.$, Figure $\left.5(\mathrm{Bb})\right)$ and 6-NPs $\left(\varepsilon_{\mathrm{r}}{ }^{\prime} 60 \mathrm{~min}=2.16\right.$, Figure $\left.5(\mathrm{Ba})\right)$, respectively. Apparently, fabricated core-shell structural configurations were capable of inducing permittivity amplification at a RF-frequency of $1.0 \mathrm{GHz}$.

We also investigated the weight ratio (cis-cup-3- $\left.\mathrm{C}_{9} / \gamma-\mathrm{FeO}_{\mathrm{x}} @ \mathrm{AuNP}\right)$-dependent dielectric property of trilayered $\left(\gamma-\mathrm{FeO}_{\mathrm{x}} @ \mathrm{AuNP}\right) @\left\{\text { cis-cup-tris }\left[\mathrm{C}_{60}\left(>\mathrm{DPAF}-\mathrm{C}_{9}\right)\right]\right\}_{\mathrm{n}}$ (5-NPs) for the comparison at the frequency of 1.0 GHz. Similar sharp increase of the permittivity at the light-off stage was found for all samples to reach a peak maximum $\left(\varepsilon_{\mathrm{r}}{ }^{\prime} \max \right)$ value of 5.46 (Figure 6(Aa)), 6.60 (Figure 6(Ab)), 7.03 (Figure 6(Ac)), and 8.39 (Figure 6(Ad)) for the weight ratio of 1:2, 1:1, 2:1, and 3:1, respectively. They can be accounted by a corresponding ratio of $\varepsilon_{\mathrm{r}}{ }^{\prime} \max / \varepsilon_{\mathrm{r}}{ }^{\prime} 0 \min$ in a $2.80-\left(\varepsilon_{\mathrm{r}}{ }^{\prime} 0 \min =1.95\right)$, 2.75- $\left(\varepsilon_{\mathrm{r}}{ }^{\prime} 0 \min =2.40\right), 2.42-\left(\varepsilon_{\mathrm{r}}{ }^{\prime} 0 \min =2.90\right)$, and 1.90-fold $\left(\varepsilon_{\mathrm{r}}{ }^{\prime} 0 \min =4.42\right)$ increase, respectively. Interestingly, a higher quantity of cis-cup-3- $\mathrm{C}_{9}$ applied led to a progressively increase of the initial 
dielectric $\varepsilon_{\mathrm{r}}{ }^{\prime}$ omin value up to 4.42 higher than that of many organic materials and polymers. This higher $\varepsilon_{\mathrm{r}}{ }^{\prime}{ }_{\text {min }}$ value resulted in a lower degree of amplification $\varepsilon_{\mathrm{r}}{ }^{\prime}{ }_{\max } / \varepsilon_{\mathrm{r}}{ }^{\prime}{ }_{0 \text { min }}$. However, a high dielectric $\varepsilon_{\mathrm{r}}{ }^{\prime} \max$ value of 8.39 (Figure 6(Ad)) achieved in organic-inorganic hybrid nanomaterials is significant for potential applications. Finally, similar calculations based on the ratio of $\varepsilon_{\mathrm{r}}{ }^{\prime} \max / \varepsilon_{\mathrm{r}}{ }^{\prime} 60 \min$ were found to be 1.82- $\left(\varepsilon_{\mathrm{r}}{ }^{\prime} 60 \min =3.0\right.$, Figure 6(Aa) $), 1.80-\left(\varepsilon_{\mathrm{r}}{ }^{\prime} 60 \mathrm{~min}=3.67\right.$, Figure $\left.6(\mathrm{Ab})\right), 1.67-\left(\varepsilon_{\mathrm{r}}{ }^{\prime} 60 \mathrm{~min}=4.21\right.$, Figure 6(Ac) ), and 1.42-fold $\left(\varepsilon_{\mathrm{r}}^{\prime}{ }^{\prime} 6 \mathrm{~min}=5.91\right.$, Figure 6(Ad) $)$ increase, respectively. Relative dielectric constant ratios of either $\varepsilon_{\mathrm{r}}{ }^{\prime} \max / \varepsilon_{\mathrm{r}}{ }^{\prime}{ }_{\min }$ or $\varepsilon_{\mathrm{r}}{ }^{\prime} \max / \varepsilon_{\mathrm{r}}{ }^{\prime} 60 \min$ as the $\varepsilon_{\mathrm{r}}{ }^{\prime}$ value shown at each peak maximum vs that at either $0 \mathrm{~min}$ or $60 \mathrm{~min}$, respectively, in Figure $6 \mathrm{~B}$ indicated a progressive increase of the degree of dielectric amplification upon the quantity increase of cis-cup-3- $\mathrm{C}_{9}$ up to a weight ratio of cis-cup-3-C $9 / \gamma-\mathrm{FeO}_{\mathrm{x}} @ \mathrm{AuNP}$ as 2.0/1.0.
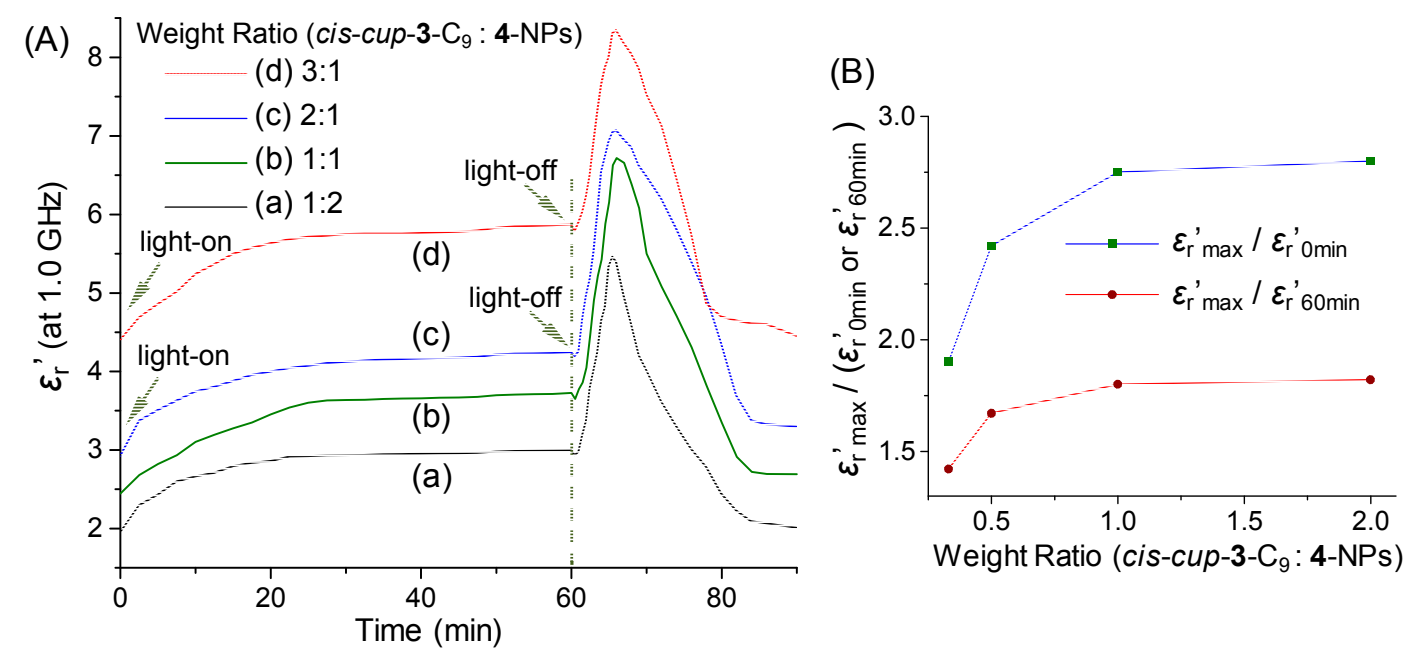

Figure 6. (A) Irradiation time-dependent relative dielectric constant $\left(\varepsilon_{\mathrm{r}}{ }^{\prime}\right)$ amplification of trilayered core-shell nanoparticles of $\left(\gamma-\mathrm{FeO}_{\mathrm{x}} @ \mathrm{AuNP}\right) @\left\{\right.$ cis-cup-tris $\left[\mathrm{C}_{60}\left(>\mathrm{DPAF}_{9} \mathrm{C}_{9}\right)\right]_{\mathrm{n}}$ (5-NPs) with a different weight ratio of cis-cup-3- $\mathrm{C}_{9}$ vs $\gamma-\mathrm{FeO}_{\mathrm{x}} @ \mathrm{AuNP}(4-\mathrm{NPs})$ at the frequency of $1.0 \mathrm{GHz}$ with a white LED light irradiation period of $60 \mathrm{~min}$. (B) Relative dielectric constant $\left(\varepsilon_{\mathrm{r}}{ }^{\prime}\right)$ ratios of the values at peak maximum vs that at either $0 \mathrm{~min}$ or $60 \mathrm{~min}$, showing a progressive increase of the degree of dielectric amplification.

\section{Experimental Section}

\subsection{Chemicals and Reagents}

Reagents of aluminum chloride $\left(\mathrm{AlCl}_{3}\right)$, tris(dibenzylideneacetone)dipalladium $(0)\left[\mathrm{Pd}_{2}(\mathrm{dba})_{3}(0)\right]$, $\alpha$-bromoacetyl bromide, rac-2,2'-bis(diphenylphosphino)-1,1'-binaphthyl (BINAP), sodium $t$-butoxide, and 1,8-diazabicyclo[5.4.0] undec-7-ene (DBU) were purchased from Aldrich Chemicals (St. Louis, MO, USA) and used without further purification. A $\mathrm{C}_{60}$ sample with a purity of $99.0 \%$ was purchased from Term USA, Inc. (Fort Bragg, CA, USA) The anhydrous grade solvent of THF was refluxed over sodium and benzophenone overnight and distilled under reduced pressure $\left(10^{-1} \mathrm{mmHg}\right)$. Sodium sulfate was used as the drying agent. The precursors 1,3,5-tris( $N$-phenylamino)benzene (TPAB) and 2-bromo-9,9-bis $\left(3^{\prime}, 5^{\prime}, 5^{\prime}\right.$-trimethyl-1'-hexyl)fluorene (BrF-C9) were synthesized according to our previous procedures [22].

\subsection{Instruments for Spectroscopic Measurements}

Infrared spectra were recorded as KBr pellets on a Thermo Nicolet AVATAR 370 FTIR spectrometer (Thermo Scientific Nicolet, Waltham, MA, USA). UV-vis spectra were recorded on a PerkinElmer Lambda 750 UV spectrometer (PerkinElmer, Shelton, CT, USA). ${ }^{1} \mathrm{H}$ NMR and ${ }^{13} \mathrm{C}$ NMR spectra were recorded on Bruker \& Spectrospin Avance 500 (Bruker, Billerica, MA, USA). The high performance 
liquid chromatography (HPLC) was performed using the $\mu$ Porasil ${ }^{\mathrm{TM}} 125 \AA$ Column $(10 \mu \mathrm{m}$, $35 \times 300 \mathrm{~mm}$, Waters, Milford, MA, USA) with a mixture of hexane-EtOAc as the mobile phase and the flow rate of $1.0 \mathrm{~mL} / \mathrm{min}$. The eluted compounds were detected by their $\mathrm{UV}$ absorption at $\lambda$ $350 \mathrm{~nm}$.

Cyclic voltammetry (CV) was record on EG\&G Princeton Applied Research 263A Potentiostat/Galvanostat (Ametek Inc., Berwyn, PA, USA) using Pt metal as the working electrode, $\mathrm{Ag} / \mathrm{AgCl}$ as the reference electrode, and $\mathrm{Pt}$ wire as the counter electrode at a scan rate of $10 \mathrm{mV} / \mathrm{s}$.

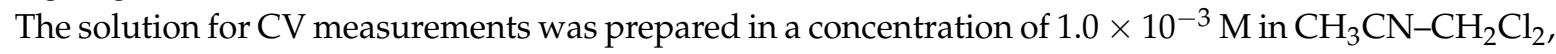
containing the electrolyte $\mathrm{Bu}_{4} \mathrm{~N}^{+}-\mathrm{PF}_{6}{ }^{-}(0.2 \mathrm{M})$. Transmission electron microscopy (TEM) measurements were carried out on Philips EM400T Transmission Electron Microscope (FEI Co., Hillsboro, OR, USA). In the sample preparation, a carbon-Copper film grid in a 200-mesh size was used as the supporting plate for directly coating of a nanoparticle sample in a solution of $1.0 \times 10^{-6} \mathrm{M}$ on the grid. All solvents were removed and dried by the freeze-dry technique to prevent the solvent-removal induced particle aggregation.

\subsection{Synthesis of $N^{1}, N^{3}, N^{5}$-Tris $\left(9,9-d i\left(3^{\prime}, 5^{\prime}, 5^{\prime}\right.\right.$-trimethyl-1'-hexyl)fluoren-2-yl)-1", $3^{\prime \prime}, 5^{\prime \prime}-$} tris(phenylamino)benzene, tris (DPAF- $\left.C_{9}\right)$ as $2-C_{9}$

Synthetic procedure of tris(DPAF- $C_{9}$ ) was followed by and slightly modified from the recently reported methods [22]. A typical procedure was given as follows. A mixture of $\mathrm{BrF}^{-\mathrm{C}_{9}}(10.0 \mathrm{~g}$, $20.3 \mathrm{mmol}$, excess), TPAB (1.16 g, $3.30 \mathrm{mmol}), \mathrm{Pd}_{2}(\mathrm{dba})_{3}(0)(0.023 \mathrm{~g}, 0.25 \mathrm{~mol} \%), \operatorname{BINAP}(0.046 \mathrm{~g}$, $0.75 \mathrm{~mol} \%)$, and sodium $t$-butoxide $(1.94 \mathrm{~g}, 20.3 \mathrm{mmol})$ taken in anhydrous toluene $(75 \mathrm{~mL})$ was heated to refluxing temperature under nitrogen for a period of $72 \mathrm{~h}$. After being cooled to room temperature, the reaction mixture was washed with water for three times and dried over sodium sulfate. A crude brown colored paste was obtained after evaporating the solvent. It was subjected to column chromatography purification using silica gel as the stationary phase and hexane-ethylacetate (9:1) as the eluent. The product of tris $\left(\mathrm{DPAF}_{-} \mathrm{C}_{9}\right)$ was collected at $R_{\mathrm{f}}=0.8$ as light yellow solids in $83 \%$ yield $(4.35 \mathrm{~g})$.

Since the HPLC indicated a mixture of tris $\left(\mathrm{DPAF}^{\left.-\mathrm{C}_{9}\right)}\right.$ stereoisomers, further separation and isolation were carried out by thin-layer chromatography (TLC), using silica gel as the stationary phase and hexane-ethylacetate $(9.5: 0.5, v / v)$ as the eluent. A mid-broad band at $R_{\mathrm{f}} 0.55-0.7$ was identified as the tris(DPAF- $\mathrm{C}_{9}$ ) products that can be cut evenly into two parts at $R_{\mathrm{f}} 0.55-0.63$ (as the bottom cut) and $R_{\mathrm{f}}$ 0.63-0.7 (as the top cut). Based on their corresponding ${ }^{1} \mathrm{H}$ NMR spectra, the top cut was confirmed to be the pure cis-cup-tris(DPAF- $\mathrm{C}_{9}$ ) stereoisomer and the bottom cut was consisting of a mixture of trans-chair-tris(DPAF-C 9 ) and cis-cup-tris(DPAF-C 9 ) stereoisomers in the ratio of roughly 2:3. This fraction was subjected to further TLC separation and elution two more times using hexane-ethylacetate $(9.7: 0.3, v / v)$ as the eluent for the first run and the similar mixture (9.8:0.2, $v / v$ ) for the second run to obtain cis-cup-tris $\left(\right.$ DPAF- $\left._{9}\right)$ in improved purity and the pure form of trans-chair-tris(DPAF-C 9 ) fraction.

Spectroscopic data of cis-cup-tris(DPAF-C $)$ ): FT-IR (KBr) $v_{\max } 3064$ (w, aromatic C-H stretching), 3038 (w), 3011 (w), 2956 (vs, aliphatic C-H stretching), 2908 (m), 2865 (s), 1596 (m), 1584 (s, C=C), 1495 (s, anti-symmetric deformations of $\mathrm{CH}_{3}$ groups and scissor vibrations of $\mathrm{CH}_{2}$ groups), $1468(\mathrm{~m})$, $1450(\mathrm{~s}), 1363$ (m, symmetric deformations of $\mathrm{CH}_{3}$ groups), 1296 (m, asymmetric stretching vibrations of C-N-C), 1246 (m, asymmetric stretching vibrations of C-N-C), $1215(\mathrm{w}), 1176(\mathrm{w}), 1157(\mathrm{w}), 1030(\mathrm{w})$, $933(\mathrm{w}), 826(\mathrm{w}), 754$ (m), 736 (s, C-H out-of-plan deformation), 710 (m, C-H out-of-plan deformation), $694(\mathrm{~m})$, and $508(\mathrm{w}) \mathrm{cm}^{-1}$; UV-vis (EtOAc, $\left.1.0 \times 10^{-5} \mathrm{M}\right) \lambda_{\max }(\varepsilon) 323\left(5.62 \times 10^{4} \mathrm{~L} \mathrm{~mol}^{-1} \mathrm{~cm}^{-1}\right)$ and $353 \mathrm{~nm}\left(5.65 \times 10^{4} \mathrm{~L} \mathrm{~mol}^{-1} \mathrm{~cm}^{-1}\right) ;{ }^{1} \mathrm{H}$ NMR $\left(500 \mathrm{MHz}, \mathrm{CDCl}_{3}\right) \delta 7.58(\mathrm{~s}, 3 \mathrm{H}, \mathrm{br}), 7.52(\mathrm{~d}, 3 \mathrm{H}), 7.32-7.21$ $(\mathrm{m}, 9 \mathrm{H}), 7.09-7.01(\mathrm{~m}, 18 \mathrm{H}), 6.82(\mathrm{t}, 3 \mathrm{H}), 6.55(\mathrm{~s}, 3 \mathrm{H}), 1.92-1.67(\mathrm{~m}, 12 \mathrm{H}), 1.10(\mathrm{~m}, 6 \mathrm{H})$, and $0.97-0.39$ $(\mathrm{m}, 96 \mathrm{H}) ;{ }^{13} \mathrm{C}$ NMR $\left(500 \mathrm{MHz}, \mathrm{CDCl}_{3}\right) \delta 151.7,150.0,149.2,147.7,146.5,141.2,136.8,129.2,126.6,126.6$, 124.0, 122.9, 121.7, 120.0, 119.3, 115.6, 54.5, 51.0, 50.6, 50.6, 38.3, 38.1, 37.4, 37.6, 33.1, 32.7, 31.1, 30.2, 
29.6, 29.4, 27.2, 22.9, and 22.4; MALDI-TOF MS calcd for $\mathrm{C}_{117} \mathrm{H}_{153} \mathrm{~N}_{3}, m / z$ 1600.21; found, $m / z 1601.26$ $\left(\mathrm{MH}^{+}\right), 1602.30,1603.29,1260.95,1092.81,752.23$ and $508.79\left(\mathrm{PhN}^{+} \mathrm{H}+\right.$ fluorene- $\left.\mathrm{C}_{9}\right)$.

Spectroscopic data of trans-chair-tris (DPAF-C 9$)$ : FT-IR $(\mathrm{KBr}) v_{\max } 3062(\mathrm{w}$, aromatic C-H stretching), 3037 (w), 3012 (w), 2955 (vs, aliphatic C-H stretching), 2925 (vs., aliphatic C-H stretching), 2855 (s), 1630 (vs), 1588 (s, C=C), 1495 (s, anti-symmetric deformations of $\mathrm{CH}_{3}$ groups and scissor vibrations of $\mathrm{CH}_{2}$ groups), 1450 (s), 1362 (m, symmetric deformations of $\mathrm{CH}_{3}$ groups), $1294(\mathrm{~m}$, asymmetric stretching vibrations of $\mathrm{C}-\mathrm{N}-\mathrm{C}), 1250(\mathrm{~m}$, asymmetric stretching vibrations of C-N-C), $1218(\mathrm{w}), 1158(\mathrm{w}), 1035(\mathrm{w}), 803$ (w), 763 (m), 736 (m, C-H out-of-plan deformation), 709 (w, C-H out-of-plan deformation), $691(\mathrm{~m})$, and $510(\mathrm{w}) \mathrm{cm}^{-1}$; UV-vis (EtOAc, $1.0 \times 10^{-5} \mathrm{M}$ ) $\lambda_{\max }$ (ع) $322\left(5.50 \times 10^{4}\right)$ and $353 \mathrm{~nm}\left(5.68 \times 10^{4} \mathrm{~L} \mathrm{~mol}^{-1} \mathrm{~cm}^{-1}\right) ;{ }^{1} \mathrm{H} \mathrm{NMR}\left(500 \mathrm{MHz}, \mathrm{CDCl}_{3}\right) \delta 7.58(\mathrm{~s}, 3 \mathrm{H}$, br), 7.51 (d, 3H), 7.34-7.20 (m, 9H), 7.09-7.01 (m, 18H), $6.84(\mathrm{~m}, 3 \mathrm{H}), 6.55(\mathrm{~m}, 2 \mathrm{H}), 6.48(\mathrm{~m}, 1 \mathrm{H}), 2.02-1.67$ $(\mathrm{m}, 12 \mathrm{H}), 1.11(\mathrm{~m}, 6 \mathrm{H})$, and $0.97-0.39(\mathrm{~m}, 96 \mathrm{H}) ;{ }^{13} \mathrm{C}$ NMR [similar to those of cis-cup-tris(DPAF-C 9$)$ ]; MALDI-TOF MS calcd for $\mathrm{C}_{117} \mathrm{H}_{153} \mathrm{~N}_{3}, m / z$ 1600.21; found, $m / z 1601.37\left(\mathrm{MH}^{+}\right), 1602.36,1603.35$, 1604.40, 1260.00, 1093.86, and $508.73\left(\mathrm{PhN}^{+} \mathrm{H}+\right.$ fluorene- $\left.\mathrm{C}_{9}\right)$.

\subsection{Synthesis of $N^{1}, N^{3}, N^{5}$-Tris(7-a-bromoacetyl-9,9-di( $3^{\prime}, 5^{\prime}, 5^{\prime}$-trimethyl-1'-hexyl)fluoren-2-yl)-1", $3^{\prime \prime}, 5^{\prime \prime}$ - tris(phenylamino)benzene, cis-cup-Tris(BrDPAF-C 9 )}

To a suspension of $\mathrm{AlCl}_{3}(1.0 \mathrm{~g}, 7.5 \mathrm{mmol})$ in 1,2-dichloroethane $(40 \mathrm{~mL})$ at $0{ }^{\circ} \mathrm{C}$ was added cis-cup-tris(DPAF-C 9 ) $(0.7 \mathrm{~g}, 0.44 \mathrm{mmol})$ with vigorously stirring. The compound of $\alpha$-bromoacetyl bromide $(1.0 \mathrm{~g}, 5.0 \mathrm{mmol})$ was then slowly added over $10 \mathrm{~min}$ while maintaining the temperature between $0-10^{\circ} \mathrm{C}$. The mixture was warmed to ambient temperature and stirred overnight. The reaction was quenched by slow addition of water $(50 \mathrm{~mL})$ while maintaining the temperature below $45^{\circ} \mathrm{C}$. The organic layer was washed sequentially with dil. $\mathrm{HCl}(1.0 \mathrm{~N}, 50 \mathrm{~mL})$ and water $(50 \mathrm{~mL} \times 2)$, and dried over sodium sulfate and then concentrated in vacuo to give the crude product as viscous yellow semi-solids. It was purified by column chromatography (silica gel) using hexane-EtOAc $(9: 1, v / v)$ as eluent to afford tris (Br-DPAF- $\left.\mathrm{C}_{9}\right)$ in $53 \%$ yield $(0.46 \mathrm{~g})$. Spectroscopic data: FT-IR $(\mathrm{KBr})$ $v_{\max } 3066(\mathrm{w}), 3035(\mathrm{w}), 2954(\mathrm{~s}), 2907(\mathrm{~m}), 2864(\mathrm{~m}), 1733(\mathrm{w}), 1675(\mathrm{~s}), 1594(\mathrm{~s}), 1584(\mathrm{~s}), 1492(\mathrm{~m})$, $1464(\mathrm{~m}), 1429(\mathrm{~m}), 1393(\mathrm{w}), 1364(\mathrm{w}), 1343(\mathrm{w}), 1288(\mathrm{~s}), 1262(\mathrm{~m}), 1205(\mathrm{w}), 1180(\mathrm{~m}), 1107(\mathrm{w})$, $1022(\mathrm{w}), 819(\mathrm{~m}), 748(\mathrm{~m}), 713(\mathrm{~m})$, and $696(\mathrm{~m}) \mathrm{cm}^{-1}$; UV-vis (EtOAc, $\left.1.0 \times 10^{-5} \mathrm{M}\right) \lambda_{\max }(\varepsilon) 304$ $\left(8.88 \times 10^{4} \mathrm{~L} \mathrm{~mol}^{-1} \mathrm{~cm}^{-1}\right)$ and $395 \mathrm{~nm}\left(1.10 \times 10^{5} \mathrm{~L} \mathrm{~mol}^{-1} \mathrm{~cm}^{-1}\right) ;{ }^{1} \mathrm{H}$ NMR $\left(500 \mathrm{MHz}, \mathrm{CDCl}_{3}\right) \delta$ $7.94(\mathrm{~m}, 3 \mathrm{H}), 7.88(\mathrm{~m}, 3 \mathrm{H}), 7.63(\mathrm{~m}, 3 \mathrm{H}), 7.56(\mathrm{~m}, 3 \mathrm{H}), 7.22-6.92(\mathrm{~m}, 21 \mathrm{H}), 6.56(\mathrm{~m}, 3 \mathrm{H}), 4.46(\mathrm{~m}, 6 \mathrm{H})$, 2.11-1.67 (m, 12H), $1.10(\mathrm{~m}, 6 \mathrm{H}), 0.99-0.26(\mathrm{~m}, 96 \mathrm{H})$.

3.5. Synthesis of $N^{1}, N^{3}, N^{5}$-Tris(7-(1,2-dihydro-1,2-methanofullerene[60]-61-carbonyl)-9,9-di( $\left(3^{\prime}, 5^{\prime}, 5^{\prime}-\right.$ trimethyl-1'-hexyl)fluoren-2-yl)-1",3",5"-tris(phenylamino)benzene, cis-cup-Tris $\left[C_{60}>\left(D P A F-C_{9}\right)\right]$ as cis-cup-3- $C_{9}$

A homogeneous solution of $\left.\mathrm{C}_{60}(0.70 \mathrm{~g}, 0.97 \mathrm{mmol})\right)$ in anhydrous toluene $(700 \mathrm{~mL})$ was prepared by ultrasonication for a period of $1.0 \mathrm{~h}$ that was then stirred overnight under nitrogen. To this was added by cis-cup-tris(BrDPAF-C 9$)(0.40 \mathrm{~g}, 0.20 \mathrm{mmol})$ and 1,8-diazabicyclo[5.4.0]undec-7-ene (DBU, $0.21 \mathrm{~g}, 1.38 \mathrm{mmol}$ ) sequentially and stirred at room temperature for a period of $8.0 \mathrm{~h}$. At the end of stirring, the reaction mixture was concentrated to a $10 \%$-volume. Methanol $(100 \mathrm{~mL})$ was added to effect precipitation of the crude product, which was isolated by centrifugation. Further purification by column chromatography (silica gel) using a solvent mixture of hexane-toluene (3:2) as the eluent afforded cis-cup-tris $\left[\mathrm{C}_{60}>\left(\mathrm{DPAF} \mathrm{C}_{9}\right)\right]$ as brown solids in $68 \%$ yield $(0.52 \mathrm{~g})$. Spectroscopic data: FT-IR (KBr) $v_{\max } 2951(\mathrm{~m}), 2923(\mathrm{~m}), 2861(\mathrm{w}), 1681(\mathrm{~m}), 1627(\mathrm{~s}), 1594(\mathrm{~s}), 1585(\mathrm{~s}), 1490(\mathrm{~m})$, $1462(\mathrm{~m}), 1429(\mathrm{w}), 1361(\mathrm{w}), 1317(\mathrm{~m}), 1292(\mathrm{~m}), 1247(\mathrm{~m}), 1213(\mathrm{~m}), 1184(\mathrm{~m}), 1093(\mathrm{w}), 1035(\mathrm{w})$, $908(\mathrm{~m}), 819(\mathrm{~m}), 732(\mathrm{~s}), 698(\mathrm{~m}), 575(\mathrm{w})$, and $529(\mathrm{~s}) \mathrm{cm}^{-1}$; UV-vis (toluene, $\left.1.0 \times 10^{-5} \mathrm{M}\right) \lambda_{\max }(\varepsilon)$ $335 \mathrm{~nm}\left(1.76 \times 10^{5} \mathrm{~L} \mathrm{~mol}^{-1} \mathrm{~cm}^{-1}\right)$ and $402 \mathrm{~nm}$ (shoulder band, $\left.4.19 \times 10^{4} \mathrm{~L} \mathrm{~mol}^{-1} \mathrm{~cm}^{-1}\right) ;{ }^{1} \mathrm{H} \mathrm{NMR}$ $\left(500 \mathrm{MHz}, \mathrm{CDCl}_{3}\right) \delta 8.46(\mathrm{~m}, 3 \mathrm{H}), 8.30(\mathrm{~m}, 3 \mathrm{H}), 7.81(\mathrm{~m}, 3 \mathrm{H}), 7.63(\mathrm{~m}, 3 \mathrm{H}), 7.31-6.70(\mathrm{~m}, 21 \mathrm{H}), 6.60(\mathrm{~m}$, $3 \mathrm{H}), 5.67(\mathrm{~m}, 3 \mathrm{H}), 1.92-1.67(\mathrm{~m}, 12 \mathrm{H}), 1.14(\mathrm{~m}, 6 \mathrm{H}), 0.70(\mathrm{~m}, 96 \mathrm{H}) ;{ }^{13} \mathrm{C} \mathrm{NMR}\left(500 \mathrm{MHz}, \mathrm{CDCl}_{3}\right) \delta$ 
$148.67,148.56,148.46,147.89,147.70,147.18,145.96,145.82,145.72,145.68,145.58,145.47,145.24,145.13$, $145.05,144.73,144.60,144.48,144.35,144.28,144.18,144.14,144.03,143.94,143.87,143.72,143.50,143.41$, $143.20,142.92,142.65,142.50,141.64,141.35,139.92,137.07,134.75,134.03,133.86,129.61,129.47,124.34$, $124.13,123.53,119.78,116.61,84.81,72.88,55.60,51.55,51.32,51.02,50.89,45.07,38.33,38.02,37.85$, $37.67,33.33,31.31,30.37,29.93,27.66$, and 22.99 .

3.6. Preparation of cis-cup-Tris $\left[\mathrm{C}_{60}>\left(D P A F-C_{9}\right)\right]$-Encapsulated $\gamma-F e O_{x} @ A u N P$ Yielding Trilayered Core-Shell Nanoparticles, $\left(\gamma-\mathrm{FeO}_{x} @ A u N P\right) @\left\{\text { cis-cup-tris }\left[\mathrm{C}_{60}\left(>\mathrm{DPAF}-\mathrm{C}_{9}\right)\right]\right\}_{n}(5-N P s)$

Nanoparticles of $\gamma-\mathrm{FeO}_{x}$ and the corresponding plasmonic metallic gold-coated $\gamma-\mathrm{FeO}_{\mathrm{x}} @ \mathrm{AuNP}$ nanoparticles (4-NPs) were synthesized according to a slightly modified procedure reported previously $[14,15]$. A large scale preparation was carried out for the subsequent fabrication procedure using the same batch of materials to give consistency of $\gamma-\mathrm{FeO}_{\mathrm{x}} @ \mathrm{AuNP}$ characteristics in terms of the particle size and the Au-layer thickness. Spectroscopy data of 4-NPs: FT-IR (KBr) $v_{\max } 3027(\mathrm{w})$, $2956(\mathrm{w}), 2923(\mathrm{~m}), 2856(\mathrm{~m}), 1631$ (s), $1492(\mathrm{~m}), 1461(\mathrm{~s}), 1378(\mathrm{~m}), 1328(\mathrm{w}), 1263(\mathrm{w}), 1166(\mathrm{w}), 1128(\mathrm{w})$, $1076(\mathrm{w}), 1037(\mathrm{w}), 804(\mathrm{~m}), 728(\mathrm{~m})$, and $588(\mathrm{~s}) \mathrm{cm}^{-1}$.

Encapsulation of cis-cup-tris[C $\left.\mathrm{C}_{60}>\left(\mathrm{DPAF}_{\mathrm{C}}\right)\right]$ on nanoparticles of $\gamma$-FeOx@AuNP was carried out by the method as follows. A mixture of $\gamma-\mathrm{FeO}_{x} @ \mathrm{AuNPs}(100 \mathrm{mg})$ and cis-cup-3-C $\mathrm{C}_{9}$ in a predefined weight ratio amount were dissolved in toluene $(30 \mathrm{~mL})$ with stirring for $30 \mathrm{~min}$ and then ultrasonicated for an additional $>30$ min until a clear solution being obtained showing a homogenized nanoparticles dispersion. The solution was concentrated via rotary evaporation to less than $3.0 \mathrm{~mL}$ in volume to increase the molecular contact of cis-cup-3-C 9 to 4-NPs. It was then diluted by toluene to a volume of $30 \mathrm{~mL}$ with stirring and subsequent sonication for $10 \mathrm{~min}$ to dissolve cis-cup-3-C 9 fully. All encapsulated magnetic nanoparticles were physically removed from the container solution by the assistance of an external permanent magnet. The separated nanoparticles were washed repeatedly by ethanol and ether, followed by drying in vacuo to afford dark brown solids of 5-NPs. Spectroscopy data: FT-IR (KBr) $v_{\max } 3089(\mathrm{w}), 3064(\mathrm{w}), 3031$ (w), 2952 (m, aromatic C-H stretching), 2927 (s, aliphatic C-H stretching), 2860 (m), 1679 (m, -C=O), 1636 (m), 1587 (s, -C=C-), 1492 (m), 1463 (m), 1430 (m), 1363 (w), 1291 (m, asymmetric stretching vibrations of C-N-C), $1247(\mathrm{w}), 1214(\mathrm{~m}), 1187(\mathrm{~m}), 1126(\mathrm{w}), 1091(\mathrm{w}), 1035(\mathrm{~m})$, $904(\mathrm{~m}), 815$ (w), 730 (m, C-H out-of-plan deformation), $695(\mathrm{~m}), 576(\mathrm{~m})$, and $526\left(\mathrm{~s}, \mathrm{C}_{60}>\right) \mathrm{cm}^{-1}$.

\subsection{Measurements of Dielectric Properties and Permittivity as Relative Dielectric Constant $\left(\varepsilon_{r}{ }^{\prime}\right)$}

Microwave-responsive dielectric property measurements were carried out by the use of an Agilent Network Analyzer (Agilent Technologies, Inc., Santa Clara, CA, USA) equipped with an open-ended Agilent 85070E dielectric probe kit in a detection range of $200 \mathrm{MHz}$ to $50 \mathrm{GHz}$. Prior to each measurement, the system base-line calibration was conducted by using open-ended, close-ended, and attenuated calibrators to ensure the minimization of signal instability that was induced by the cable connection and system drift errors. In the data collection, a complex scattering parameter, defined as $\mathrm{S}_{11}$, was measured and converted to relative complex electric dielectric constant values using Agilent 85071E Materials Measurement Software. This complex form of dielectric constant $\left(\varepsilon^{*}\right)$ consists of both a real $\left(\varepsilon_{\mathrm{r}}{ }^{\prime}\right)$ and an imaginary $\left(\varepsilon_{\mathrm{r}}{ }^{\prime \prime}\right)$ part. The former term represents the value of dielectric constant and the latter is defined as the loss factor.

All permittivity measurements were performed in a custom-built chamber that was conducted under a circumferentially uniform illumination environment. The uniformness was achieved by the installation of a reflective half-circular aluminum plate at the back-wall side surrounding the testing tube which was located at the center of the chamber. The light source used in this measurement included a collimated white LED light with an output power of $2.0 \mathrm{~W}$ (Prizmatix, Southfield, MI, USA). The light beam was allowed to pass through a small window opening at the front side of the chamber for the sample irradiation. Some reflected light beams were designed to refocus from the back-side aluminum mirror plate back to the sample-containing tube. We installed four small fans with two at the top and one at each side-wall of the chamber to control and prevent the temperature increase inside the 
chamber during the experiment. The illumination period was fixed at $60 \mathrm{~min}$. Poly(dimethylsiloxane) (PDMS, $1.0 \mathrm{~g}$ ) semi-solid was applied as a polymer matrix host which is capable of forming a paste-like material sample in mixing with a predefined quantity of nanoparticles. In a typical preparation, a mixture of PDMS and core-shell nanoparticle materials $(100 \mathrm{mg})$ were blended by dissolving both components in ethyl acetate $(20 \mathrm{~mL})$ in a testing tube under sonication. It was followed by solvent evaporation to yield paste-like semi-solid materials filling in the tube.

\section{Conclusions}

We designed and synthesized novel 3D-configurated stereoisomers cis-cup-tris[ $\left.\mathrm{C}_{60}>\left(\mathrm{DPAF}_{\mathrm{C}} \mathrm{C}_{9}\right)\right]$ and trans-chair-tris $\left[\mathrm{C}_{60}>\left(\mathrm{DPAF}_{-} \mathrm{C}_{9}\right)\right]$ in good yields. Efficient chromatographic separation was carried out to obtain both stereoisomers in a pure form with their corresponding nanostructure verified by spectroscopic techniques. The former with three $\mathrm{C}_{60}>$ cages per molecule facing at the same side of the geometrical molecular cup-shape was proposed to provide excellent binding interaction forces at the gold surface of core-shell $\gamma-\mathrm{FeO}_{\mathrm{x}} @$ AuNP nanoparticles to direct the subsequent formation of a fullerene cage array (defined as fullerosome). Upon photoactivation of the Au-layer and cis-cup-tris $\left[\mathrm{C}_{60}>\left(\mathrm{DPAF}_{-} \mathrm{C}_{9}\right)\right]$ itself, the level of photoinduced intramolecular $\mathrm{e}^{-}$-transfer from DPAF to $\mathrm{C}_{60}>$ moieties was found to be largely enhanced by the accumulated plasmonic resonance energy at the near-field surface. Distribution of resulting negative charges along the outer $\left(\mathrm{C}_{60}>\right)$-derived fullerosome shell layer of the trilayered NPs was correlated with the detected photoswitchable dielectric amplification changes using white LED light at $1.0 \mathrm{GHz}$. This class of new materials exhibits potential in microwave applications as its photoswitching responsive wavelength range is being extended to cover WiFi-bands over 2.4/3.6/5.0 GHz.

Author Contributions: All authors contribute a significant effort on this work. H.Y. and M.W. carried out the main synthetic works, spectroscopic characterization, data analysis, and permittivity measurements; T.Y. setup the permittivity and reflectivity measurements and carried out dielectric properties conversion; T.Y., L.-S.T. and L.Y.C. participated in the discussion and experimental studies and contributed to a part of manuscript writing; All authors read and approved the final manuscript.

Funding: The authors at UML thank the financial support of Air Force Office of Scientific Research (AFOSR) under the grant number FA9550-14-1-0153.

Conflicts of Interest: The authors declare no conflicts of interest.

\section{References}

1. Sharma, M.; Singh, M.P.; Srivastava, C.; Madras, G.; Bose, S. Poly(vinylidene fluoride)-based flexible and lightweight materials for attenuating microwave radiations. ACS Appl. Mater. Interfaces 2014, 6, 21151-21160. [CrossRef] [PubMed]

2. Gadinski, M.R.; Chanthad, C.; Han, K.; Dong, L.; Wang, Q. Synthesis of poly(vinylidene fluoride-co-bromotrifluoroethylene) and effects of molecular defects on microstructure and dielectric properties. Polym. Chem. 2014, 5, 5957-5966. [CrossRef]

3. Wei, R.; Li, K.; Ma, J.; Zhang, H.; Liu, X. Improving dielectric properties of polyarylene ether nitrile with conducting polyaniline. J. Mater. Sci. Mater. Electron. 2016, 27, 9565-9571. [CrossRef]

4. You, Y.; Du, X.; Mao, H.; Tang, X.; Wei, R.; Liu, X. Synergistic enhancement of mechanical, crystalline and dielectric properties of polyarylene ether nitrile-based nanocomposites by unidirectional hot stretching-quenching. Polym. Int. 2017, 66, 1151-1158. [CrossRef]

5. Lei, D.; Runt, J.; Safari, A.; Newnham, R.E. Dielectric properties of azo dye-poly(methyl methacrylate) mixtures. Macromolules 1987, 20, 1797-1801. [CrossRef]

6. Puli, V.S.; Pradhan, D.K.; Riggs, B.C.; Chrisey, D.B.; Katiyar, R.S. Investigations on structure, ferroelectric, piezoelectric and energy storage properties of barium calcium titanate (BCT) ceramics. J. Alloys Compd. 2014, 584, 369-373. [CrossRef]

7. Kim, K.K.; Hsu, A.; Jia, X.; Kim, S.M.; Shi, Y.; Dresselhaus, M.; Palacios, T.; Kong, J. Synthesis and characterization of hexagonal boron nitride film as a dielectric layer for graphene devices. ACS Nano 2012, 6, 8583-8590. [CrossRef] [PubMed] 
8. Wypych, A.; Bobowska, I.; Tracz, M.; Opasinska, A.; Kadlubowski, S.; Krzywania-Kaliszewska, A.; Grobelny, J.; Wojciechowski, P. Dielectric properties and characterisation of titanium dioxide obtained by different chemistry methods. J. Nanomater. 2014, 2014, 124814. [CrossRef]

9. You, Y.; Han, W.; Tu, L.; Wang, Y.; Wei, R.; Liu, X. Doublelayer core/shell-structured nanoparticles in polyarylene ether nitrile-based nanocomposites as flexible dielectric materials. RSC Adv. 2017, 7, 29306-29311. [CrossRef]

10. Chu, B.; Zhou, X.; Ren, K.; Neese, B.; Lin, M.; Wang, Q.; Bauer, F.; Zhang, Q.M. A dielectric polymer with high electric energy density and fast discharge speed. Science 2006, 313, 334-336. [CrossRef] [PubMed]

11. Khanchaitit, P.; Han, K.; Gadinski, M.R.; Li, Q.; Wang, Q. Ferroelectric polymer networks with high energy density and improved discharged efficiency for dielectric energy storage. Nat. Commun. 2013, 4, 2845. [CrossRef] [PubMed]

12. Li, Q.; Yao, F.-Z.; Liu, Y.; Zhang, G.; Wang, H.; Wang, Q. High-temperature dielectric materials for electrical energy storage. Annu. Rev. Mater. Res. 2018, 48, 219-243. [CrossRef]

13. Brebels, J.; Manca, J.V.; Lutsen, L.; Vanderzande, D.; Maes, W. High dielectric constant conjugated materials for organic photovoltaics. J. Mater. Chem. A 2017, 5, 24037-24050. [CrossRef]

14. Wang, M.; Yu, T.; Tan, L.-S.; Urbas, A.; Chiang, L.Y. Tunability of rf-responses by plasmonic dielectric amplification using branched $\mathrm{e}^{-}$-polarizable $\mathrm{C}_{60}$-adducts on magnetic nanoparticles. J. Phys. Chem. C 2016, 120, 17711-17721. [CrossRef]

15. Wang, M.; Su, C.; Yu, T.; Tan, L.-S.; Hu, B.; Urbas, A.; Chiang, L.Y. Novel photoswitchable dielectric properties on nanomaterials of electronic core-shell $\gamma-\mathrm{FeO}_{\mathrm{x}} @ \mathrm{Au} @$ fullerosomes for $\mathrm{GHz}$ frequency applications. Nanoscale 2016, 8, 6589-6599. [CrossRef] [PubMed]

16. Wang, M.; Yu, T.; Tan, L.-S.; Urbas, A.; Chiang, L.Y. Enhancement of photoswitchable dielectric property by conducting electron donors on plasmonic core-shell gold-fluorenyl $\mathrm{C}_{60}$ nanoparticles. J. Phys. Chem. C 2018, 122, 12512-12523. [CrossRef]

17. Padmawar, P.A.; Canteenwala, T.; Tan, L.-S.; Chiang, L.Y. Synthesis and characterization of photoresponsive diphenylaminofluorene chromophore adducts of [60]fullerene. J. Mater. Chem. 2006, 16, 1366-1378. [CrossRef]

18. Jeon, S.; Wang, M.; Ji, W.; Tan, L.-S.; Cooper, T.; Chiang, L.Y. Broadband two-photon absorption characteristics of highly photostable fluorenyl-dicyanoethylenylated [60]fullerene dyads. Molecules 2016, 21, 647. [CrossRef] [PubMed]

19. Padmawar, P.A.; Rogers, J.O.; He, G.S.; Chiang, L.Y.; Canteenwala, T.; Tan, L.-S.; Zheng, Q.; Lu, C.; Slagle, J.E.; Danilov, E.; et al. Large cross-section enhancement and intramolecular energy transfer upon multiphoton absorption of hindered diphenylaminofluorene- $C_{60}$ dyads and triads. Chem. Mater. 2006, 18, 4065-4074. [CrossRef]

20. Luo, H.; Fujitsuka, M.; Araki, Y.; Ito, O.; Padmawar, P.; Chiang, L.Y. Inter- and intramolecular photoinduced electron-transfer processes between $\mathrm{C}_{60}$ and diphenylaminofluorene in solutions. J. Phys. Chem. B 2003, 107, 9312-9318. [CrossRef]

21. Lee, Y.-T.; Wang, M.; Kokubo, K.; Kang, N.-G.; Wolf, L.; Tan, L.-S.; Chen, C.-T.; Chiang, L. New 3D-stereoconfigurated cis-tris(fluorenylphenylamino)-benzene with large steric hindrance to minimize $\pi-\pi$ stacking in thin-film devices. Dyes Pigm. 2018, 149, 377-386. [CrossRef]

22. Kang, N.-G.; Kokubo, K.; Jeon, S.; Wang, M.; Lee, C.-L.; Canteenwala, T.; Tan, L.-S.; Chiang, L. Synthesis and photoluminescent properties of geometrically hindered cis-tris(diphenyl-aminofluorene) as precursors to light-emitting devices. Molecules 2015, 20, 4635-4654. [CrossRef] [PubMed]

23. Wang, M.; Jeon, S.; Su, C.; Yu, T.; Tan, L.-S.; Chiang, L.Y. Synthesis of photoswitchable magnetic $\mathrm{Au}$-fullerosome hybrid nanomaterials for permittivity enhancement applications. Molecules 2015, 20, 14746-14760. [CrossRef] [PubMed]

24. Verma, S.; Hauck, T.; El-Khouly, M.E.; Padmawar, P.A.; Canteenwala, T.; Pritzker, K.; Ito, O.; Chiang, L.Y. Self-assembled photoresponsive amphiphilic diphenylaminofluorene- $\mathrm{C}_{60}$ conjugate vesicles in aqueous solution. Langmuir 2005, 21, 3267-3272. [CrossRef] [PubMed]

25. Kuzume, A.; Herrero, E.; Feliu, J.M.; Nichols, R.J.; Schiffrin, D.J. Fullerene monolayers adsorbed on high index gold single crystal surfaces. Phys. Chem. Chem. Phys. 2004, 6, 619-625. [CrossRef]

26. Islam, M.T.; Molugu, S.K.; Cooke, P.H.; Noveron, J.C. Fullerene stabilized gold nanoparticles. New J. Chem. 2015, 39, 5923. [CrossRef] 
27. Agilent Technologies. Basics of Measuring the Dielectric Properties of Materials; Agilent Technical Note 5989-2589EN; Agilent Technologies: Santa Clara, CA, USA, 2006; pp. 17-18.

28. Nicolson, A.M.; Ross, G.F. Measurement of the intrinsic properties of materials by time-domain techniques. IEEE Trans. Instrum. Meas. 1970, 19, 377-382. [CrossRef]

29. Pillai, S.; Green, M.A. Plasmonics for photovoltaic applications. Sol. Energy Mater. Sol. Cells 2010, 94, 1481-1486. [CrossRef]

30. Losurdo, M.; Giangregorio, M.M.; Bianco, G.V.; Sacchetti, A.; Capezzuto, P.; Bruno, G. Enhanced absorption in Au nanoparticles/a-Si:H/c-Si heterojunction solar cells exploiting Au surface plasmon resonance. Sol. Energy Mater. Sol. Cells 2009, 93, 1749-1754. [CrossRef]

31. Coronado, E.A.; Ezequiel, R.E.; Stefani, F.D. Optical properties of metallic nanoparticles: Manipulation light, heat and forces at the nanoscale. Nanoscale 2011, 3, 4042-4059. [CrossRef] [PubMed]

Sample Availability: Samples of all synthetic compounds including cis-cup-tris(BrDPAF-C 9 ) and cis-cup-tris $\left[\mathrm{C}_{60}>\left(\mathrm{DPAF}_{\mathrm{F}}\right)\right]$ are available from the authors.

(C) 2018 by the authors. Licensee MDPI, Basel, Switzerland. This article is an open access article distributed under the terms and conditions of the Creative Commons Attribution (CC BY) license (http://creativecommons.org/licenses/by/4.0/). 